\title{
Internal Training Load Perceived by Athletes and Planned by Coaches: A Systematic Review and Meta-Analysis
}

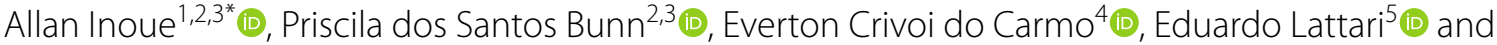 \\ Elirez Bezerra da Silva ${ }^{1,2}$ (1)
}

\begin{abstract}
Background: Rating of perceived exertion (RPE) and session RPE (SRPE) has been widely used to verify the internal load in athletes. Understanding the agreement between the training load prescribed by coaches and that perceived by athletes is a topic of great interest in sport science.
\end{abstract}

Objective: This systematic review and meta-analysis aimed to investigate differences between the training/competition load perceived by athletes and prescribed/intended/observed by coaches.

Methods: A literature search (September 2020 and updated in November 2021) was conducted using PubMed, Web of Science, Embase, and SPORTDiscus databases. The protocol was registered in the Open Science Framework (osf. io/wna4x). Studies should include athletes and coaches of any sex, age, or level of experience. The studies should present outcomes related to the RPE or sRPE for any scale considering overall training/competition sessions (physical, strength, tactical, technical, games) and/or classified into three effort categories: easy, moderate, and hard.

Results: Twenty-seven studies were included in the meta-analysis. No difference was found between coaches and athletes for overall RPE $(S M D=0.19, P=0.10)$ and overall SRPE $(S M D=0.05, P=0.75)$. There was a difference for easy $\operatorname{RPE}(\mathrm{SMD}=-0.44$, small effect size, $P=0.04)$ and easy sRPE (SMD $=-0.54$, moderate effect size, $P=0.04)$. No differences were found for moderate RPE $(S M D=0.05, P=0.74)$ and hard RPE $(S M D=0.41, P=0.18)$. No difference was found for moderate $(S M D=-0.15, P=0.56)$ and hard $(S M D=0.20, P=0.43)$ SRPE.

Conclusion: There is an agreement between coaches and athletes about overall RPE and sRPE, and RPE and sRPE into two effort categories (moderate and hard). However, there were disagreements in RPE and SRPE for easy effort category. Thus, despite a small disagreement, the use of these tools seems to be adequate for training monitoring. Keywords: Internal training load, External training load, Rating of perceived exertion, Session rating of perceived exertion

\footnotetext{
*Correspondence: allan_inoue@hotmail.com

${ }^{1}$ Exercise and Sport Sciences Postgraduate Program, Rio de Janeiro State University, Rio de Janeiro, Brazil

Full list of author information is available at the end of the article
}

\section{Key Points}

- The session rating of perceived exertion (sRPE) may be used to indicate the internal training load in several sports.

- The ratings of perceived exertion (RPE) and sRPE in easy sessions prescribed/intended/observed by coaches may underestimate athletes' RPE/sRPE. 
- The RPE and sRPE may guide coaches' and sport scientists' decision-making in training programming in several sports.

\section{Introduction}

Several studies have shown the importance of training load monitoring in various sports modalities [1-3]. High training loads without adequate recovery may trigger unwanted adaptations and negative results, whereas loads with insufficient duration and intensities may not generate necessary adaptations to improve physical performance $[4,5]$. In this sense, precise training load control and manipulation are required [6]. Traditionally, training load has been measured by power, velocity, acceleration, movement repetition count, and global positioning system (GPS) parameters [6]. This way of measuring the athletes' training load has been called external load. In turn, the emerging literature has measured the physiological stress imposed on the athlete during training or competitions, defined as internal load. Heart rate, blood lactate, oxygen consumption, rating of perceived exertion (RPE), and session RPE (sRPE) have been widely used to verify the internal load in athletes [7].

The use of technological tools to control training load (heart rate monitors, GPS, smartphone apps, etc.) is a reality of contemporary training monitoring. However, the large amount of information can become a real problem for coaches' analysis. Additionally, using these equipments involves a cost that varies widely from hundreds to thousands of dollars [8]. These values increase when we need to monitor many athletes simultaneously. Foster et al. [9] recommend keeping it simple, which may be the most crucial element of training monitoring. Thus, the use of RPE and sRPE is considered an easy-to-use, non-invasive, accessible, valid, and reliable method for coaches to assess the training load applied to athletes daily, improving the control of training variables [2, 10-13].

The sRPE method uses an objective measure of training load (time) interacting with a subjective one (RPE), thus giving a training load index in arbitrary units (a.u.) $[2,14]$ extensively accepted as a marker of the internal training load [13]. In addition, the sRPE has been used to assess the agreement between coach and athlete for load planned and perceived [5]. Previous studies $[15,16]$ have shown good agreement between coaches and athletes. For instance, Redkva et al. [16] found no differences when comparing the sRPE prescribed by the coaches and perceived by the athletes in physical, technical, and tactical training sessions during the three weeks of pre-season in soccer players. However, some studies [5, 17-19] have reported a difference between the training load planned by coaches and the load perceived by athletes. In general, these disagreements between coaches and athletes were identified in the prescribed training as easy or hard [5, 17-19]. Besides, Rabelo et al. [20] demonstrated that in all three effort categories (easy, moderate, and hard), the athletes perceived a lower training load than intended by the coach. Foster et al. [17], based on empirical observations, suggest that this lack of correspondence between the program planned by the coach and that carried out by the athletes is a potential cause of the high incidence of negative results in sports training. In this scenario, incorrect interpretation of sRPE data can lead to errors in the control and subsequent planning of training. The training program is prescribed to balance overload and recovery [2], determining the positive or negative adaptation of the training stimulus. It is known that too low a training load can result in detraining status [21]. On the other hand, too high a training load and poor recovery can result in overtraining syndrome $[4,22]$ and developing overuse injuries [23]. Therefore, the balance between training load and recovery represents a significant challenge for coaches and athletes.

We acknowledge that recent studies investigated the internal load in several sports (for reviews, see $[3,6]$ ). However, no systematic review and meta-analysis were performed to elucidate and summarize the differences between the internal load perceived by the athletes and that planned/intended/observed by the coaches. Giving daily control with feedback to coaches is the key to improving physical performance and decreasing the risk of injuries and harmful effects of training. An example is manipulating the future training load to re-align with the planned load [20]. Coaches should be aware that athletes could interpret the same training differently. A simple and subjective method to quantify the internal load of the designed and executed training programs could serve as a tool to optimize the training process $[9,13]$. Therefore, this systematic review and meta-analysis of the literature aimed to investigate whether there are differences between the training load perceived by athletes and that prescribed/intended/observed by coaches. We hypothesized that significant differences would be found between that expected by coaches and that perceived by the athletes [5, 17-19].

\section{Methods}

\section{Protocol and Registration}

This systematic review and meta-analysis was written according to the Preferred Reporting Items for Systematic Reviews and Meta-Analysis (PRISMA) [24]. The protocol was registered in the Open Science Framework in 
September 2020, with storage in Australia-Sydney (Available at: osf.io/wna4x).

\section{Search Strategy}

A systematic literature search was conducted in September 2020 and updated in November 2021. The following databases were used: PubMed, Web of Science, Embase, and SPORTDiscus. The following descriptors were used: "SRPE," OR "Session rating of perceived exertion," OR "Session RPE," OR “Session-RPE," OR “Training dose," OR "Ratings of perceived exertion," OR "Training load," OR "Training loads," OR "Internal load," OR "Internal training load," OR "External load," OR "External training load," AND "Coaches," OR "Coach," OR "Mismatch between coaches-players perceptions," OR "Coaches-players perceptions," OR "Discrepancy between coach-athlete perceptions," OR "Comparison of athlete-coach perceptions," OR "Impaired player-coach perceptions," OR "Relationship between coach-athlete perceptions." In addition, the reference lists were explored to find additional relevant studies. No filters were applied in the search as a limitation of time and language.

\section{Eligibility Criteria}

Eligibility criteria for study inclusion consisted of one of the following: (a) Population: athletes and coaches of any sport (individual or team), sex, age, or experience level; (b) Comparison: between the training/competition (all season periods) load prescribed/intended/observed by the coaches and that performed/reported/perceived by the athletes; (c) Outcome: RPE or sRPE for any scale considering overall training/competition sessions (physical, strength, tactical, technical, games) and/or classified into three effort categories: easy, moderate and hard. These three effort categories were adopted because they are the three intensity zones typically used in the literature related to the comparison of RPE/sRPE between coaches and athletes [5, 17-20, 25-34]; (d) Study design: crosssectional studies published in peer-reviewed journals. Conference abstracts, dissertations, theses, book chapters, and articles published in non-peer-reviewed journals were not included.

\section{Study Selection}

Study eligibility assessments were performed independently by two reviewers (AI and PB). First, studies were downloaded from EndNote (version X9.0, Clarivate Analytics, Philadelphia, PA, USA), and duplicates were removed before being selected by title and abstract. Then, the full texts of the remaining studies were retrieved and evaluated for eligibility. Any disagreements regarding the inclusion of a particular study were resolved through a consensus meeting. When there was no consensus, the third researcher (ES) decided whether to include or exclude the study.

\section{Data Extraction}

The following data were extracted from the articles: participant characteristics, sample size, training level, type of sports, the scale used, intensity zones, number of sessions/training duration, number of coaches, coaches' experience time, number of athletes, and results. Importantly, data extraction from the selected studies was processed independently by two researchers (AI and PB). Differences were resolved through a consensus meeting or a third reviewer (ES) decision. When the data to be extracted were not found, the principal authors were contacted. When no response was obtained from the principal authors, the data imputation technique using the Kinovea 0.8.15 software was used to extract data reported in figures.

\section{Assessment of Methodological Quality}

To assess the methodological quality of the included studies, we used the Quality Assessment Tools for Observational Cohort and Cross-Sectional Studies (Available in: https://www.nhlbi.nih.gov/health-topics/study-quali ty-assessment-tools). Reviewers answered each question as "Yes," "No," "Cannot determine," "Not applicable," or "Not reported," based on the critical review of each study. Questions answered with "Yes" received a score of 1, while questions answered with "No," "Cannot determine," or "Not reported" received a score of 0 . The total score for each study was used to rank the risk of bias as low $(6-8)$, moderate (3-5), or high (0-2). The methodological quality assessment was performed independently by two experienced evaluators (AI and PB). Any disagreements were resolved through a consensus meeting or a third reviewer (ES) decision.

\section{Certainty of Evidence}

Two evaluators (AI and PB) independently assessed the certainty of evidence using the Grading of Recommendations Assessment, Development and Evaluation (GRADE) approach [35] through the GRADE PRO website (https://gradepro.org). GRADE specifies four categories: high, moderate, low, and very low, applied to a body of evidence [35]. The observational studies included in this review started with low certainty of evidence. Five aspects can decrease the certainty of evidence (a) risk of bias (decreased if more than $25 \%$ of participants were from studies with a moderate or high risk of bias); (b) inconsistency of results (decreased if heterogeneity $I^{2}>50 \%$ ); (c) indirect evidence (decreased if the outcomes evaluated are not those of primary interest); (d) imprecision (decreased if less than 140 participants were 
included in the comparison) and (e) other (e.g., publication bias). Three aspects can increase the certainty of evidence (a) effect size (increased if large effect size), (b) dose-response gradient (increased if study effect size increases due to an increase in an independent variable), and (c) confounding factors (increased if the main potential confounding variables were measured and adjusted statistically). For each aspect that met the criterion, the certainty was increased by one level. If the criterion was not satisfied, the certainty was decreased by one level [35]. Any disagreements were resolved through a consensus meeting or a third reviewer (ES) decision.

\section{Statistical Analysis}

A meta-analysis was performed through the Review Manager software (RevMan Version 5.4; the Nordic Cochrane Centre, Copenhagen: Cochrane Collaboration). Each standardized mean difference (SMD) was weighted according to the inverse variance method. The SMD values in each trial were pooled with a random (if heterogeneity was significant) or fixed-effects model (if heterogeneity was by chance). SMD values of $0.2,0.5$, and 0.8 represent small, moderate and large effect sizes, respectively [36]. Heterogeneity between studies was assessed using $\mathrm{I}^{2}$ statistics. $\mathrm{I}^{2}$ values between $0-50 \%$ represent low heterogeneity, between 50 and $74 \%$ moderate heterogeneity and $\geq 75 \%$ high heterogeneity [37]. Funnel plots and Egger's regression analysis were also performed using StatsDirect software (Version 3). They were used to assess publication bias. Statistical significance was set at $5 \%(P \leq 0.05)$.

\section{Results}

\section{Selection of Studies}

The results identified a total of 5,388 articles. Four additional records were identified through direct citation search and manual verification of article reference lists. After removing duplicate reports $(n=887)$, a total of 4505 articles remained. A summary of the search results and reasons for exclusion are shown in Fig. 1. Twentynine studies were included in this systematic review and 27 in meta-analysis since two studies failed to report the standard deviation of the coach rating of exertion. Data are summarized in Table 1.

\section{Study Characteristics}

This review contains 725 participants (306 men, 163 women, and 256 unspecified). Of the 29 studies included in the review, 12 studies included only male participants $[5,15,16,20,29,31,38-43]$, four studies included only female participants [44-47], three studies did not specify the sex of the participants [26, 30, 48], and 10 studies included a combination of male and female participants [17-19, 27, 28, 31-34, 49].

All 29 studies recruited only athletes. The evaluated sports were swimming $(n=4)$, soccer $(n=4)$, tennis $(n=1)$, middle and long distance running $(n=1)$, crosscountry running $(n=1)$, beach volleyball $(n=1)$, volleyball $(n=2)$, track and field $(n=1)$, basketball $(n=3)$, open-water swimmers $(n=1)$, karate $(n=1)$, road cycling and mountain biking $(n=1)$, futsal $(n=2)$, handball $(n=1)$, paralympic swimmers $(n=1)$, judo $(n=1)$, road cycling $(n=1)$, and combination of different sports $(n=2)$ including volleyball, basketball, soccer, hockey, netball and rugby union.

The studies were published between the years 1997 to 2021. The number of training sessions ranged from one to 3024. The number of coaches ranged from 1 to 9. Of the 29 studies included in the review, eight studies included two coaches $[5,15,16,18,19,39,42,44]$, two studies had three coaches [17, 40], six studies included four coaches [30, 32, 45-48], one study included five coaches [29], one study included six coaches [49], and two studies included nine coaches $[26,41]$. The coaches' experience ranged from $\leq 1$ year to $>23$ years. Fourteen studies did not report the length of experience of coaches $[15,17-19,25,28,30,31,33,41,42,45,46,48]$.

\section{Differences Between Intensity Zones (Easy, Moderate, and Hard)}

The included studies used different scales to categorize the intensity zones into easy, moderate, and hard. The most used was the Borg CR10 Scale $(n=22)$. However, the Borg Scale 6 to $20(n=6)$ and a generic 0 -to10 -point scale without images using the Omni verbal cues for adults (OMNI; $n=1$ ) were also used. Moreover, different cutoff values were used to classify sessions into easy, moderate, and hard. Considering the Borg CR10 Scale, training sessions were classified as easy $(\mathrm{RPE}<3)$, moderate (RPE 3-5), and hard (RPE $>5$ ) in nine studies [17-19, 25-27, 29, 31, 33]. In the study by Scantlebury et al. [32], the sessions were classified as easy (RPE 1-2), moderate (RPE 3-4), and hard (RPE 5-10). In the study by Figueiredo et al. [15], the training intensity was classified as easy $(R P E<4)$, moderate $(R P E \geq 4$ to $\leq 7)$, and hard $(\mathrm{RPE}>7)$. Ieno et al. [28] classified the sessions as easy $(\mathrm{RPE} \leq 3)$, moderate (RPE 4-6), and hard ( $R P E \geq 7$ ). Besides, a 2-step cluster with log-likelihood as the distance measure and Schwartz's Bayesian criterion was performed to classify the training load into easy, moderate, and hard sessions based on the Borg CR10 Scale [20]. Using the Borg scale 6 to 20, Brink et al. [5] classified the training sessions as easy $(\mathrm{RPE}<13)$, moderate (RPE 13-14), and hard (RPE >14). In the study by Voet et al. [34], the sessions were classified as easy $(\mathrm{RPE}<11)$, 

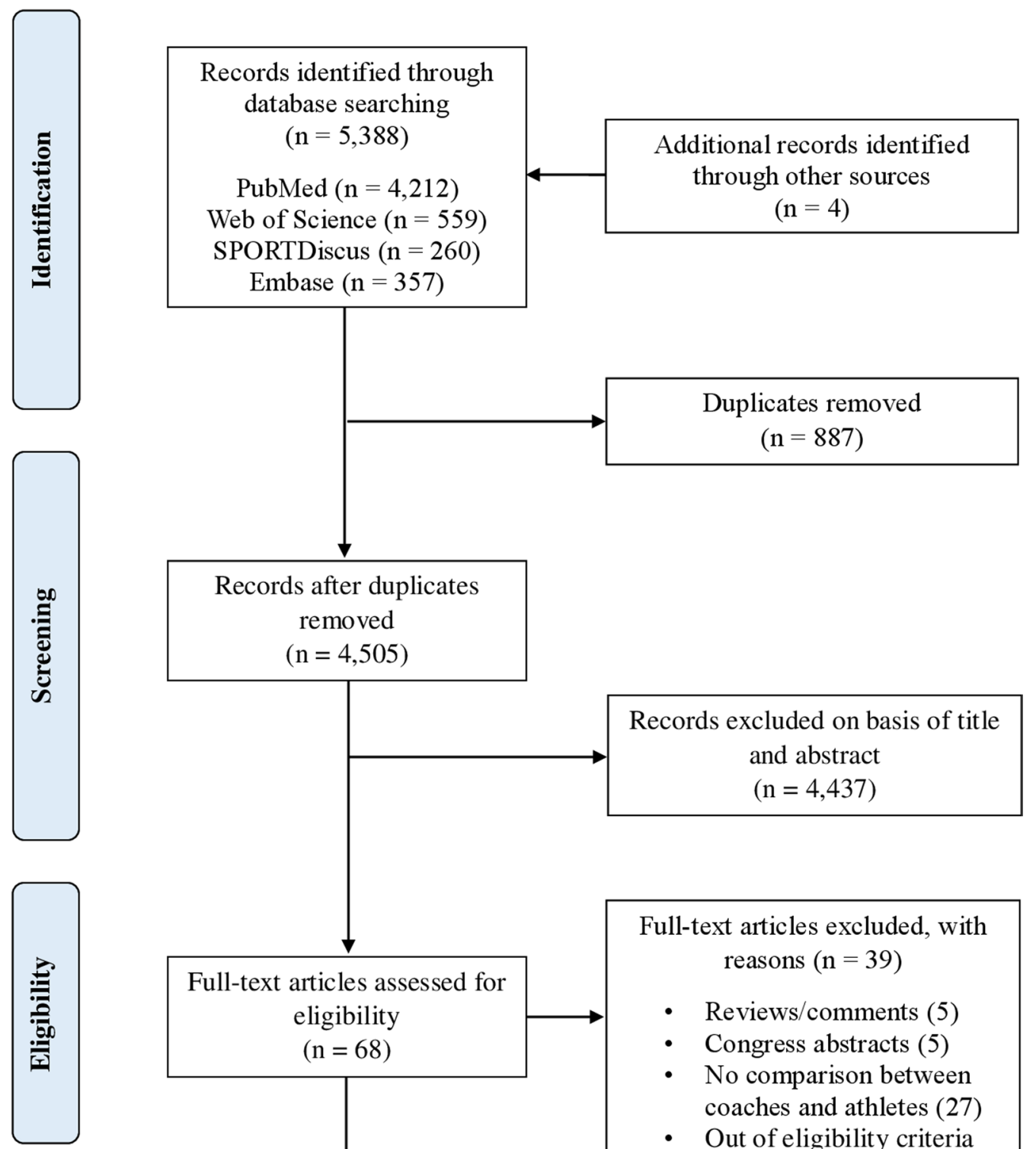

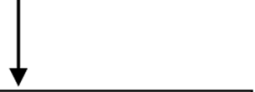

Full-text articles assessed for eligibility ( $\mathrm{n}=68)$

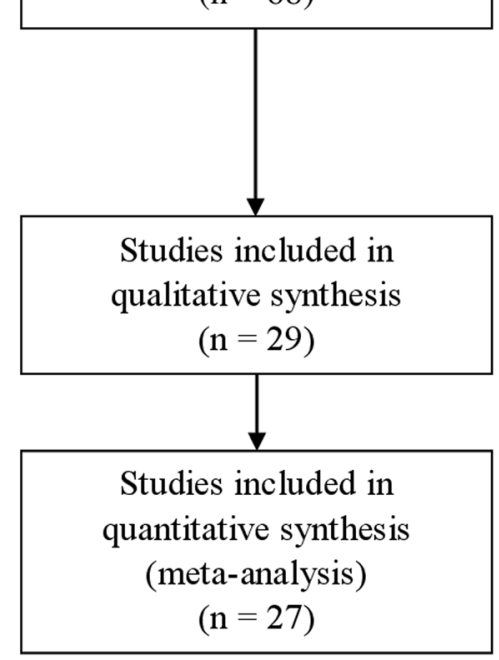

Full-text articles excluded, with reasons $(n=39)$

- Reviews/comments (5)

- Congress abstracts (5)

- No comparison between coaches and athletes (27)

- Out of eligibility criteria (2)

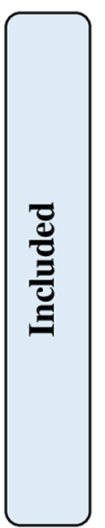

Fig. 1 Literature search flowchart 


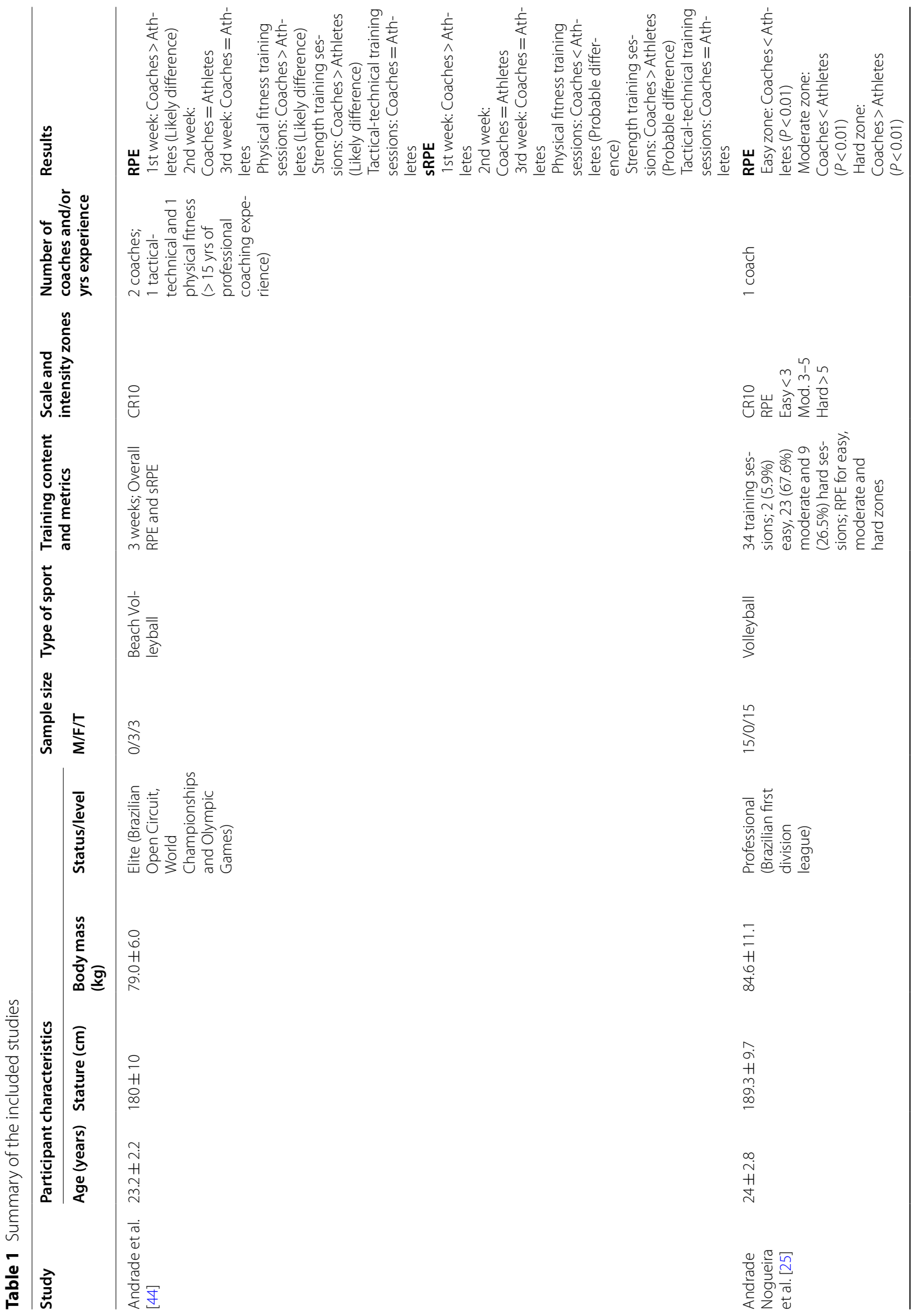




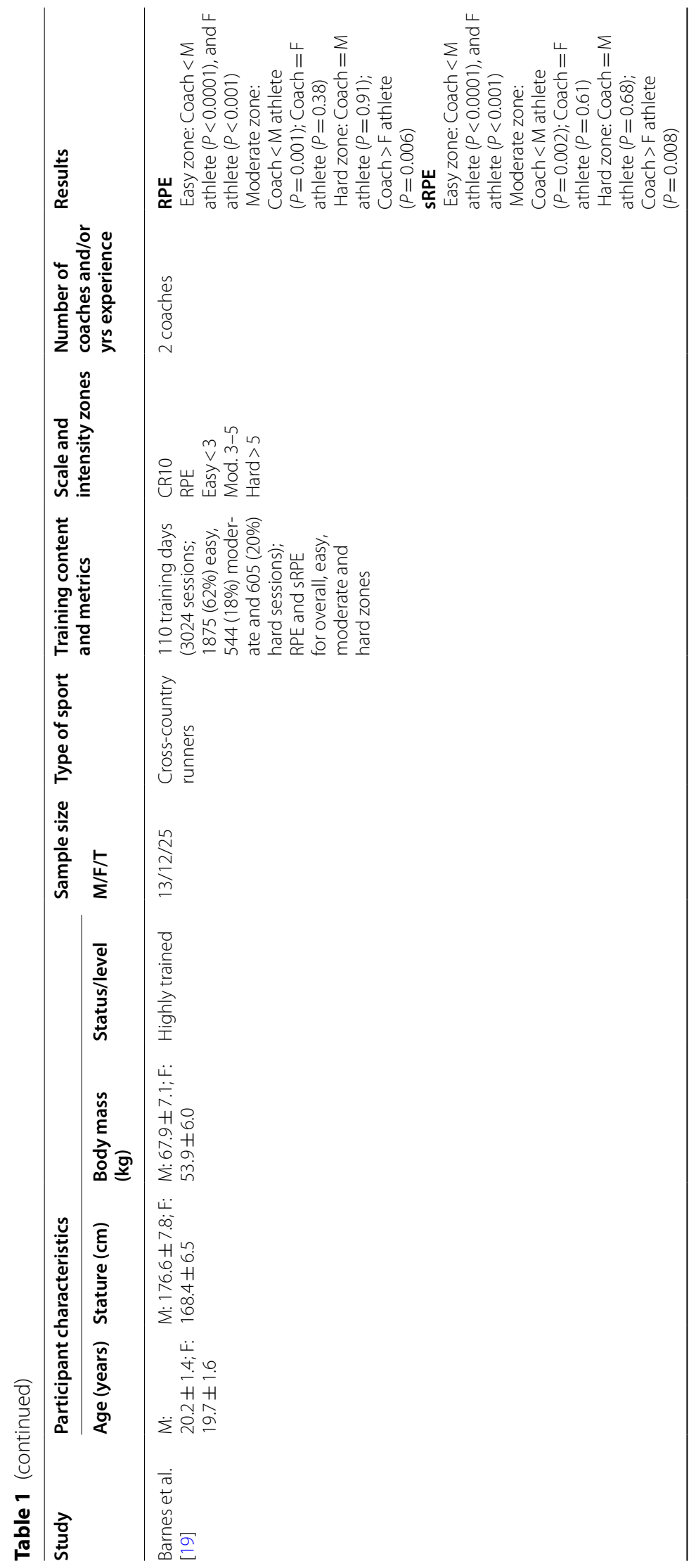




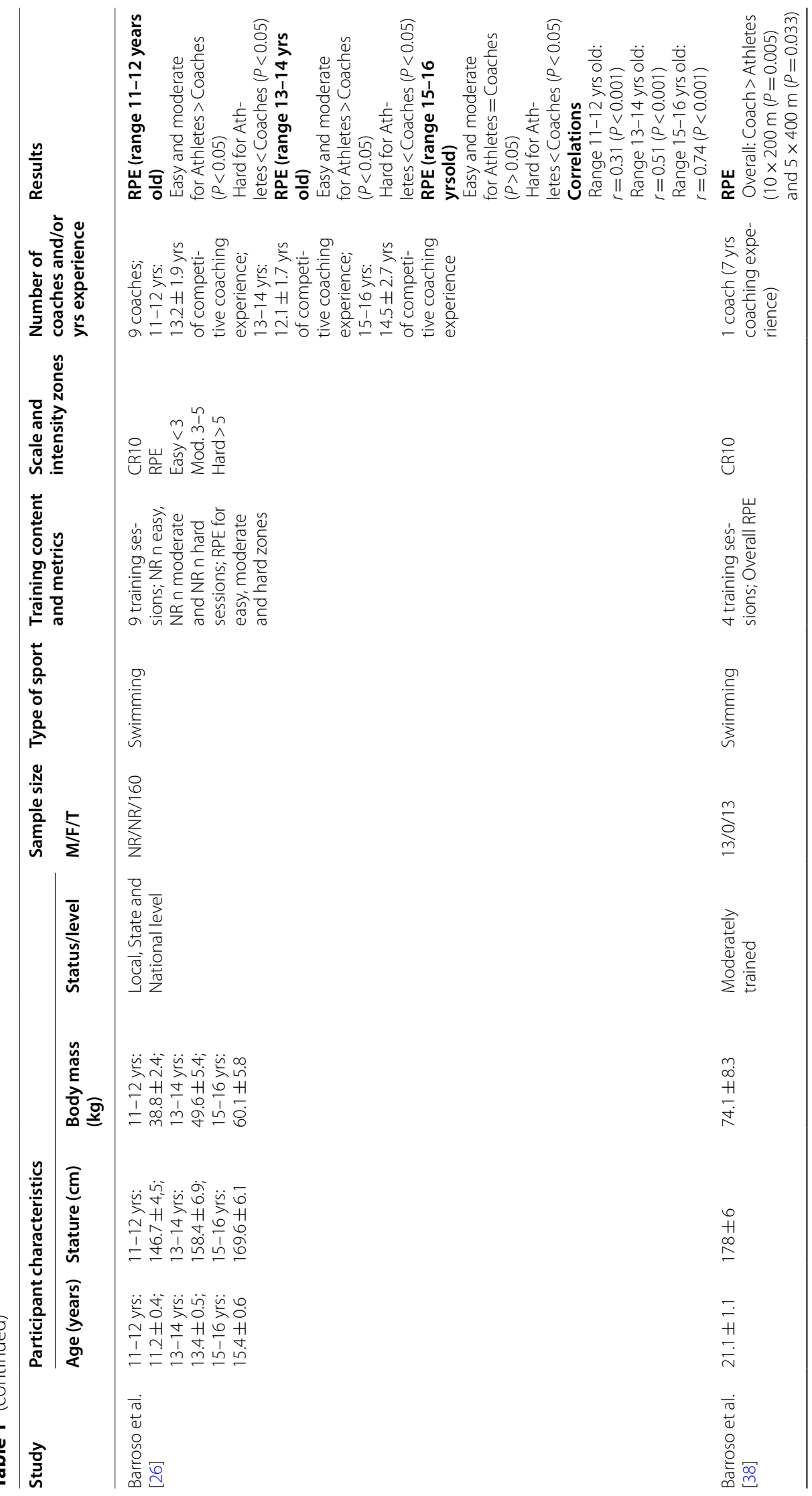




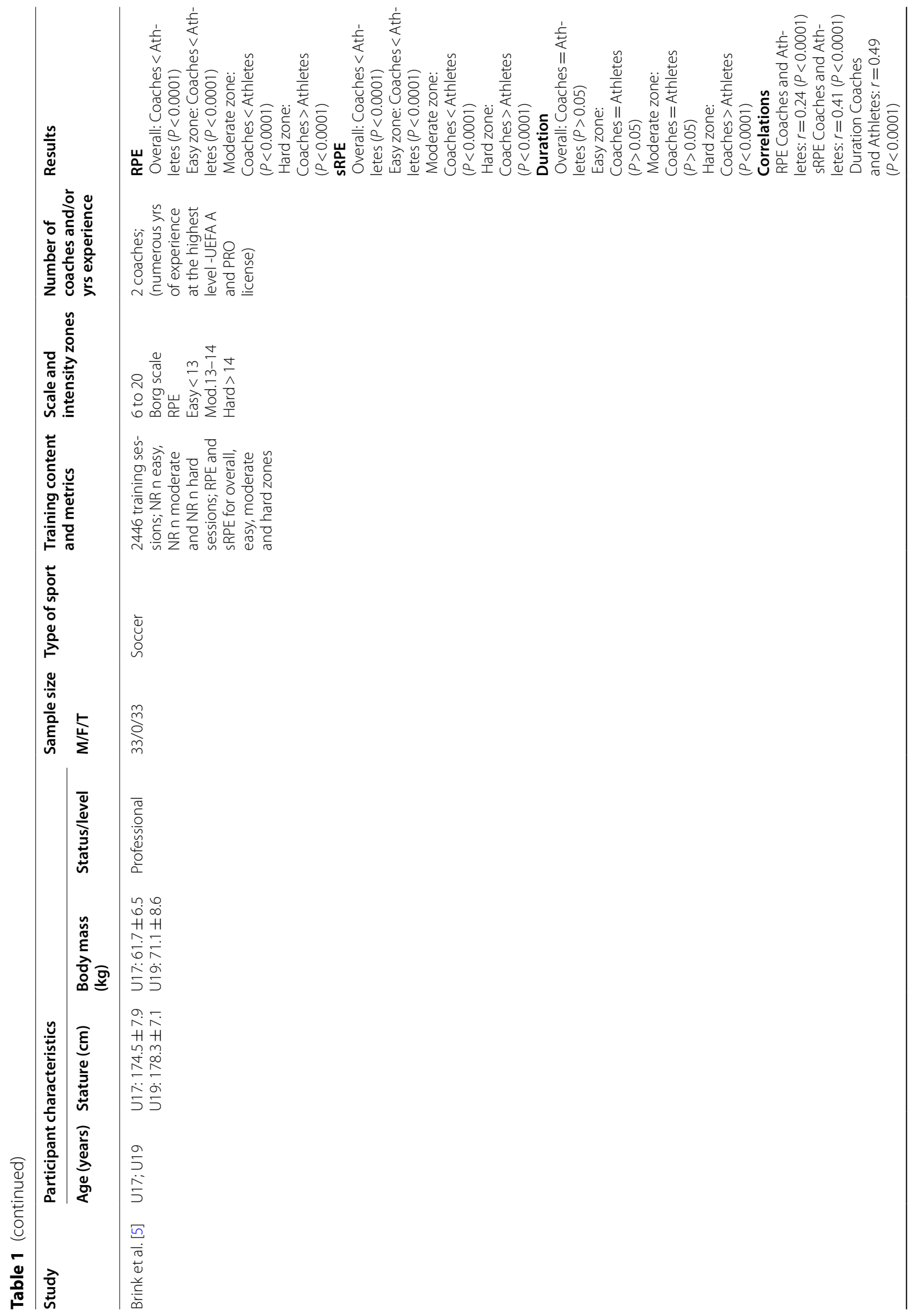


Inoue et al. Sports Medicine-Open $\quad$ (2022) 8:35

Page 10 of 32

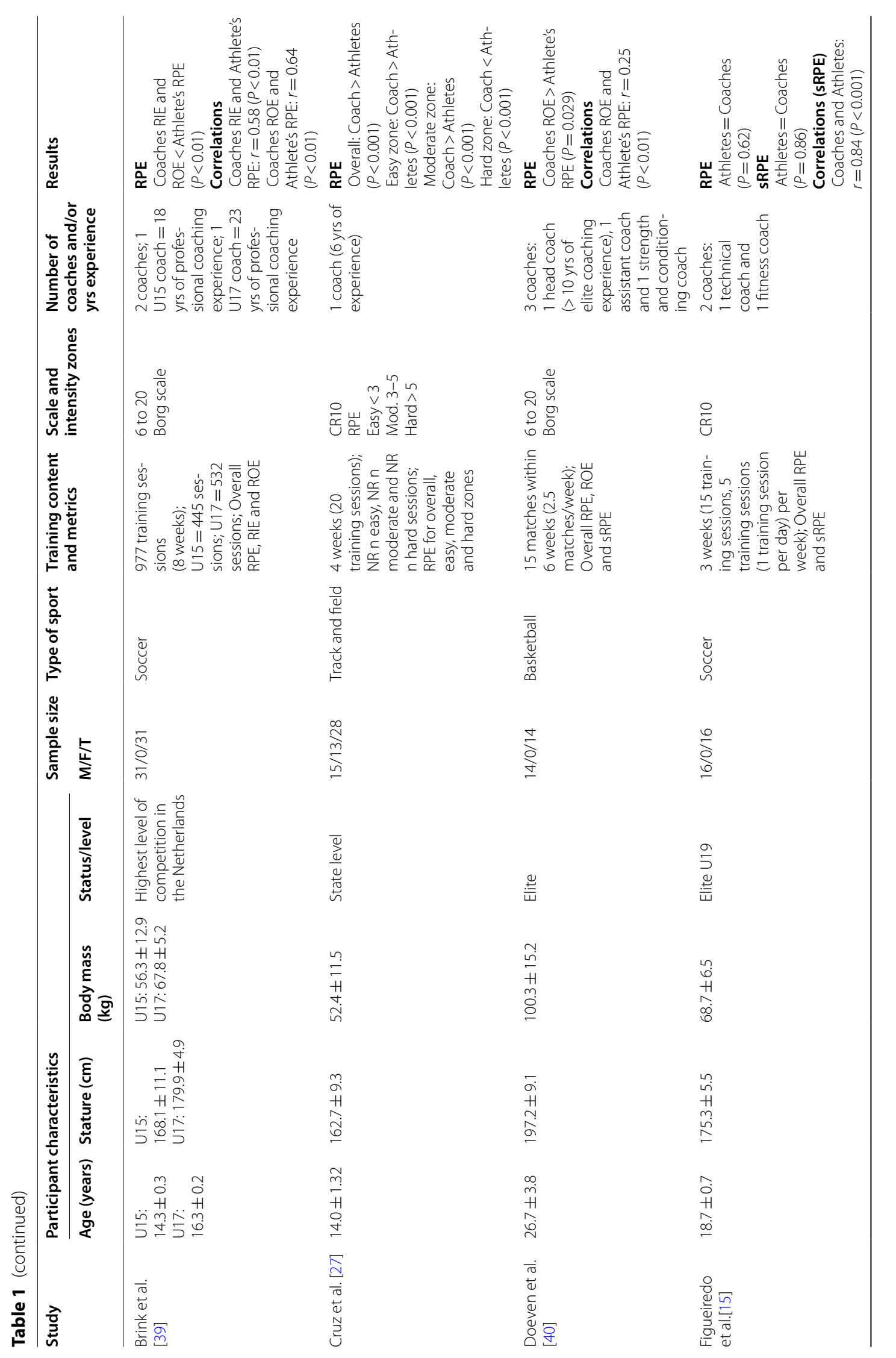




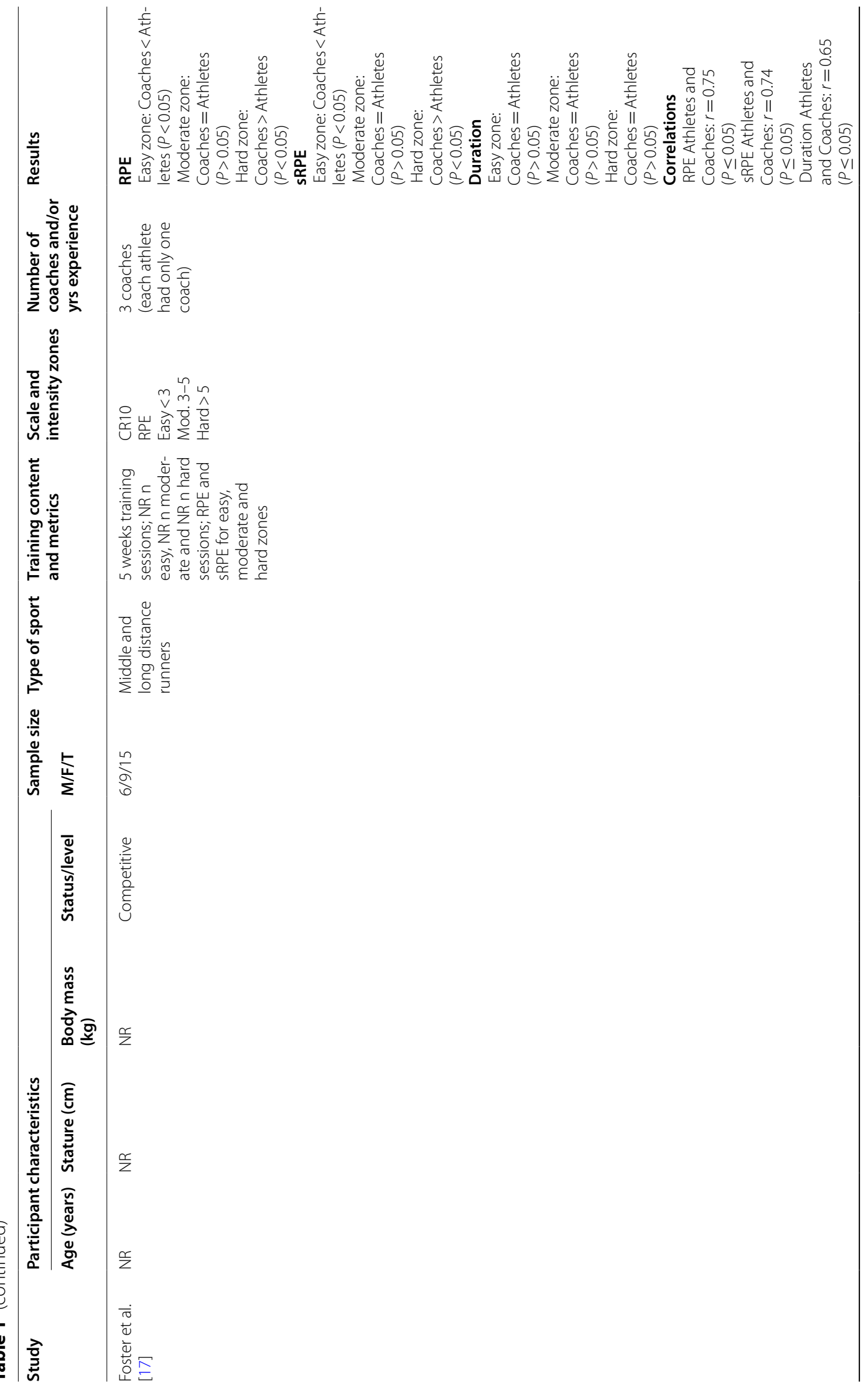




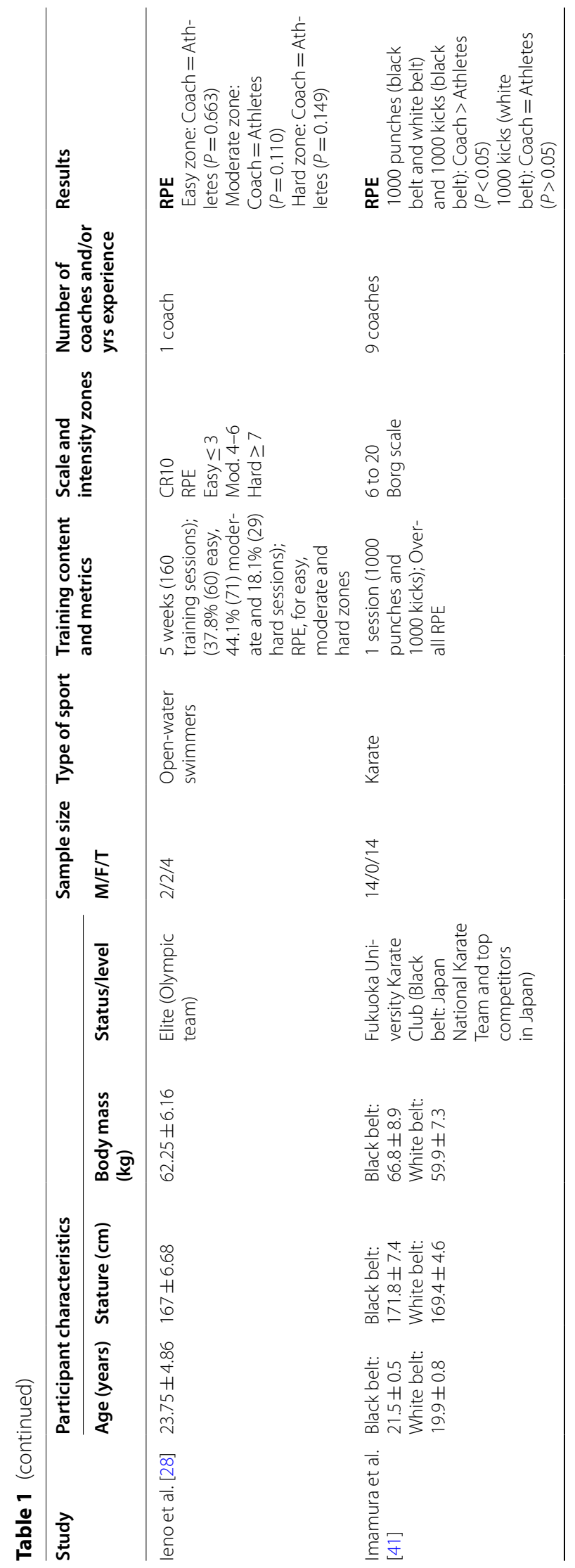




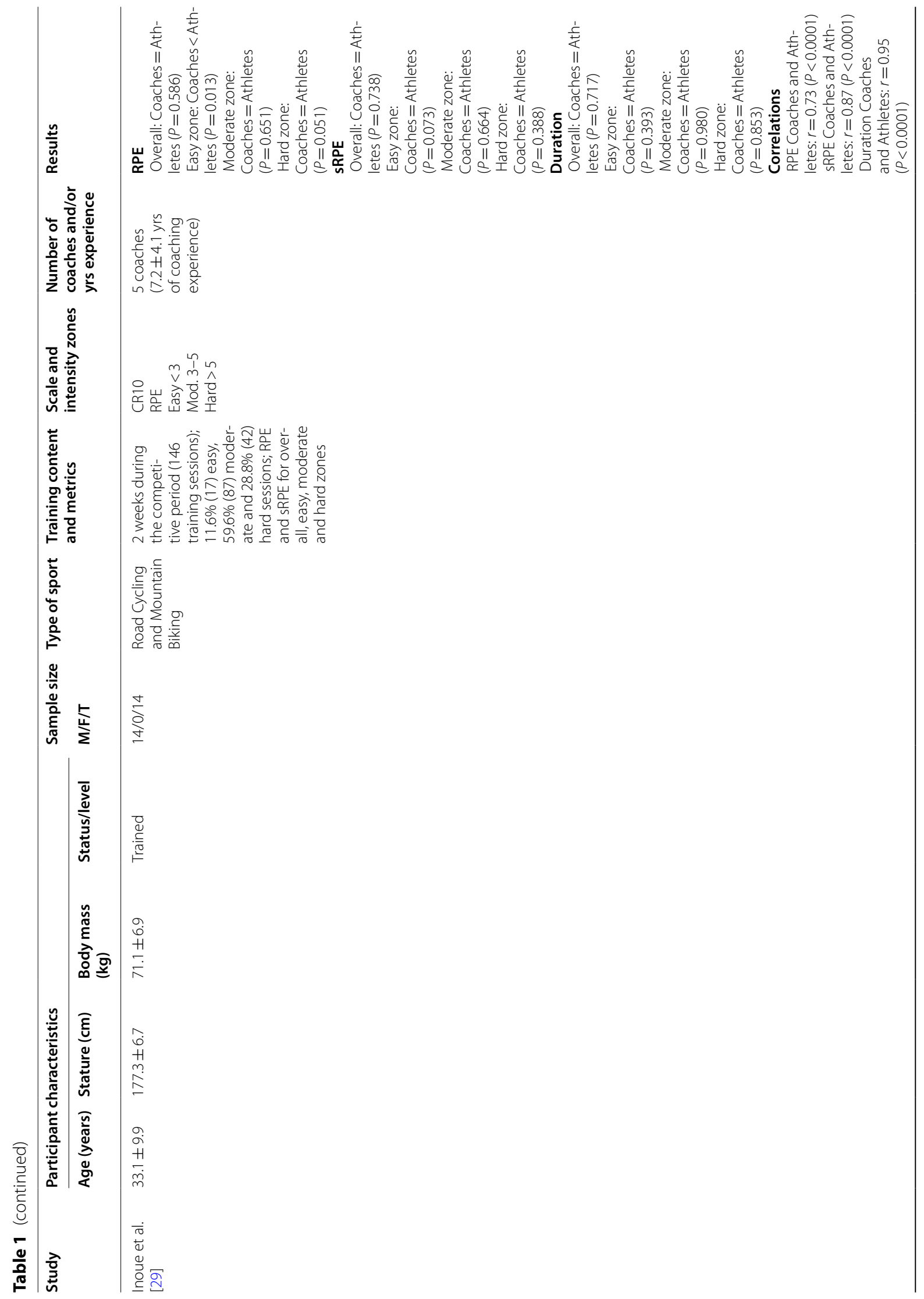




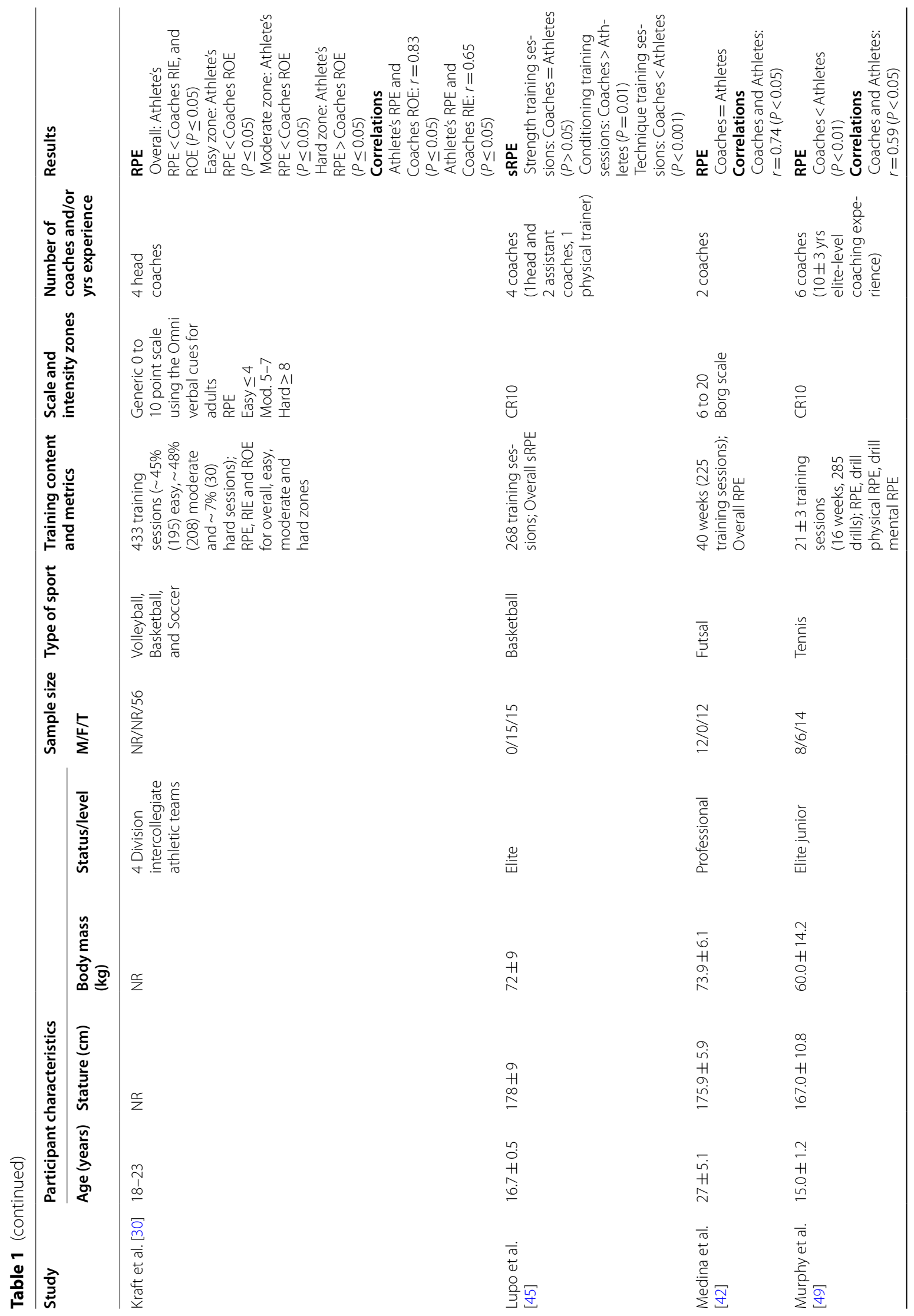




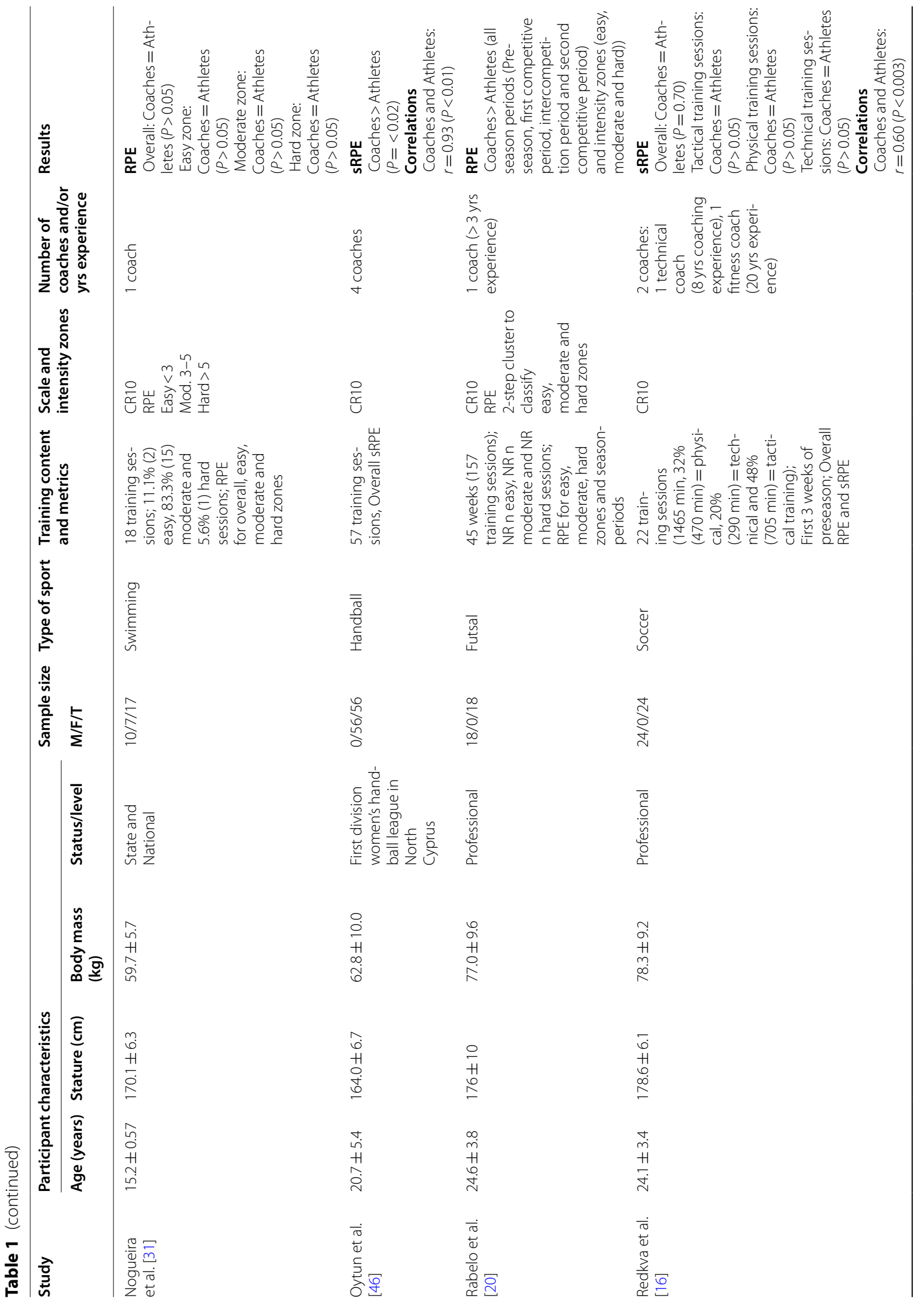




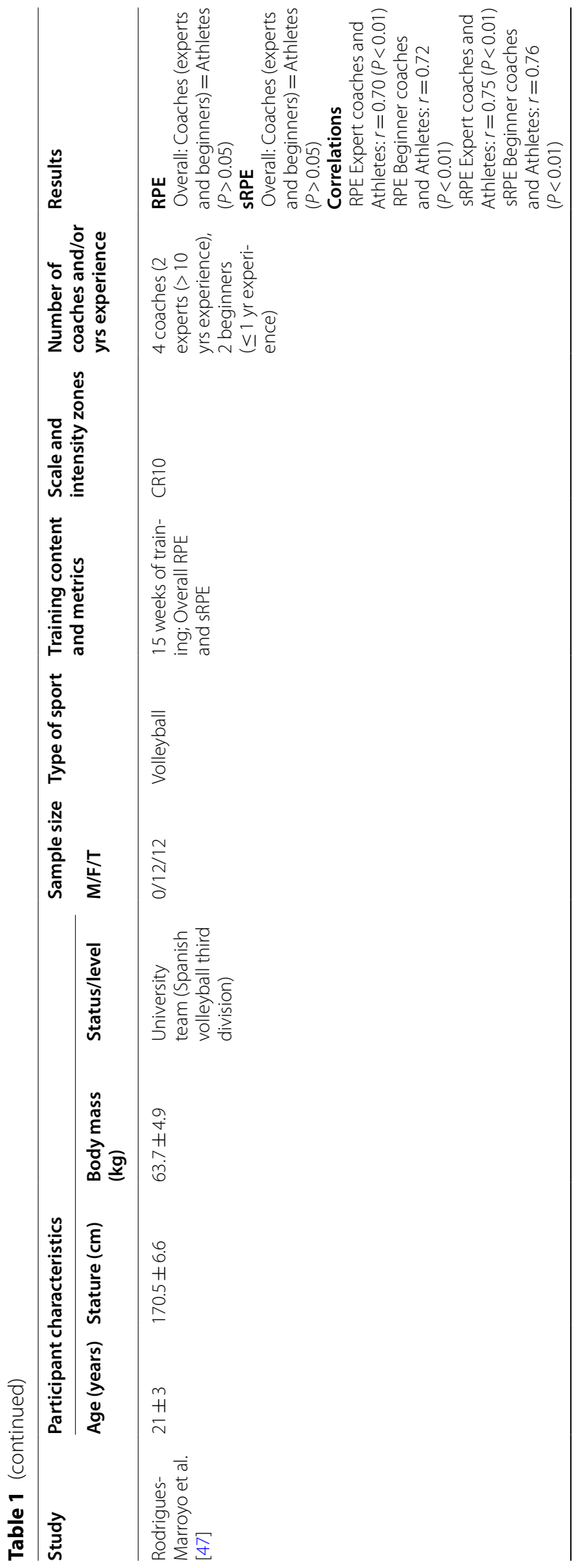




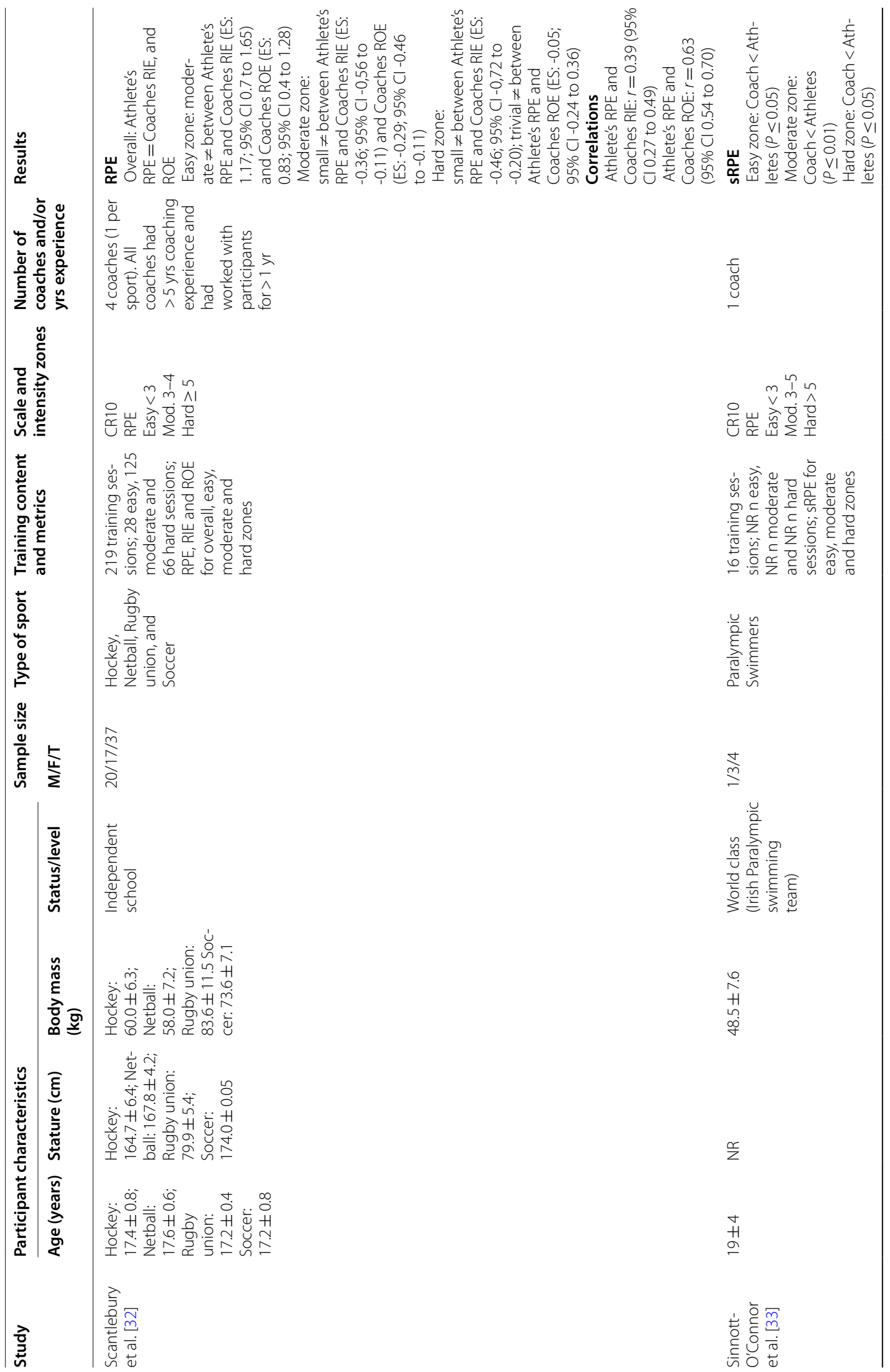




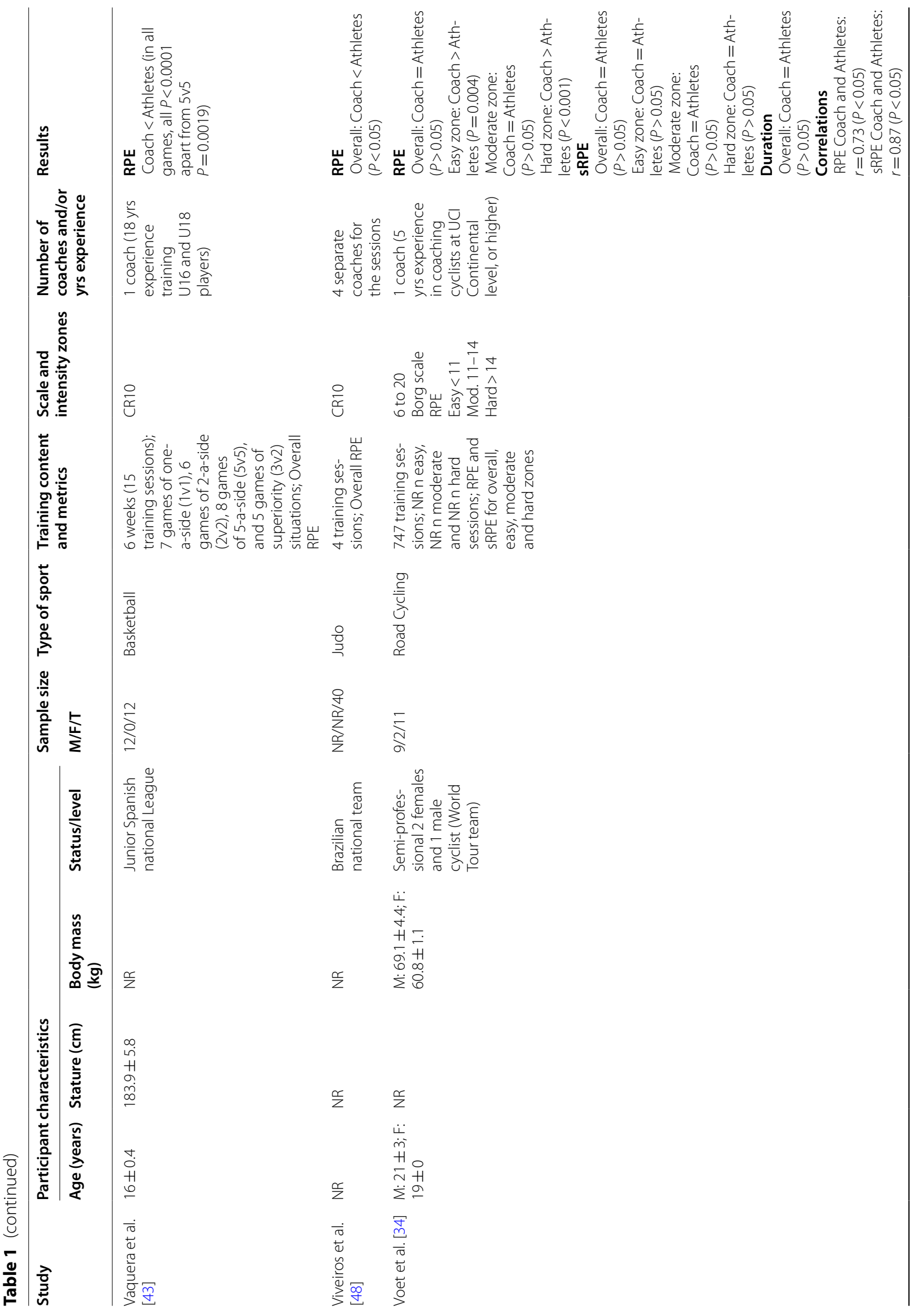




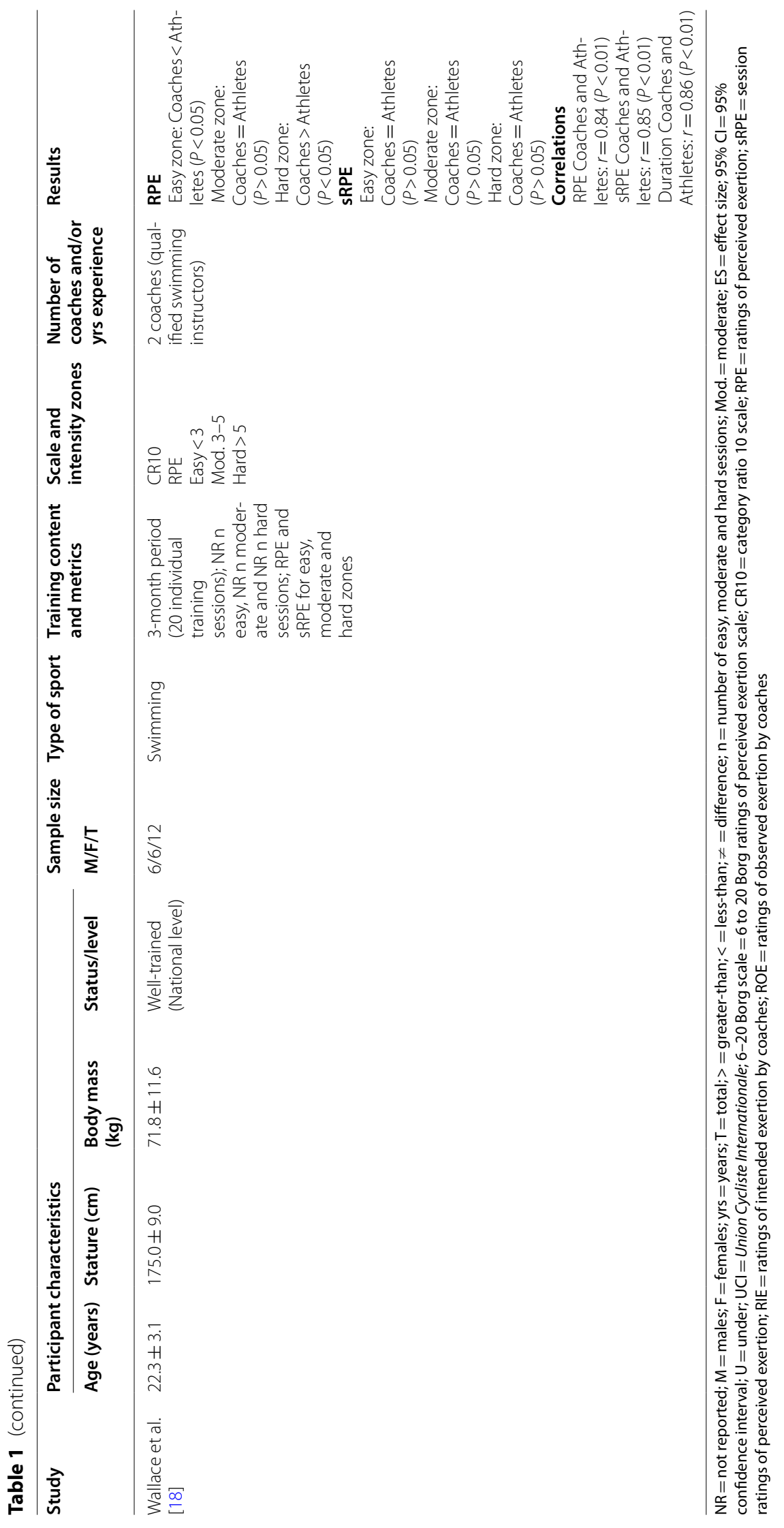


moderate (RPE 11-14), and hard (RPE > 14). Unlike previous studies, Kraft et al. [30] used the athletes' perceptions to classify the training sessions as easy $(\mathrm{RPE} \leq 4)$, moderate (RPE 5-7), and hard ( $R P E \geq 8$ ). In turn, the categorization was based on the verbal anchor descriptors of the scale used (OMNI from 0 to 10 points): RPE (4="Somewhat easy", $6=$ "Somewhat hard," and $8=$ "Hard").

\section{Study Quality Assessment}

The bias scores of the studies included in this systematic review and meta-analysis ranged from four (moderate risk of bias) to six (low risk of bias) out of eight possible points (Table 2). Items 6 and 7 were answered with "No" in all 29 studies following the guidelines of the Quality Assessment Tool of the National Institutes of Health for Observational Cohort and Cross-sectional Studies because they are cross-sectional studies. Items $3,8,9,10$, 12 , and 13 were considered not applicable to the crosssectional studies included in this review. Therefore, eight items $(1,2,4,5,6,7,11$, and 14) were considered to assess the methodological quality of the studies.

Six studies were classified as having a low risk of bias $[15,19,32,39,45,49]$, while twenty-three were classified as having a moderate risk of bias $[5,16-18,20,25-31,33$, $34,38,40-44,46-48]$. All studies in this review included the research question or objective (item 1 ), clearly specified the study population (item 2), and all subjects were selected or recruited from the same or similar populations (item 4). Twenty-three studies [5, 16-18, 20, 25-31, $33,34,38,40-44,46-48]$ did not present key potential confounding variables measured and adjusted statistically (item 14).

\section{Certainty of Evidence}

Using the GRADE approach, the certainty of evidence was very low (Table 3). The downgraded aspects were risk of bias and imprecision, and none of the aspects (effect size, dose-response gradient, or confounding factors) increased the certainty of evidence.

\section{Meta-Analysis Results}

A low heterogeneity $\left(\chi^{2}=41.66, \quad d f=33, \quad P=0.14\right.$; $\left.I^{2}=21 \%\right)$ was observed in studies that compared overall RPE between coaches and athletes. Likewise, a low heterogeneity $\left(\chi^{2}=3.72, \quad d f=20, \quad P=1.00 ; \quad I^{2}=0 \%\right)$ was observed in studies that compared overall sRPE between coaches and athletes. When comparing the RPE between coaches and athletes in the three effort categories (easy, moderate, and hard), a low heterogeneity was observed for easy category $\left(\tau^{2}=0.35\right.$; $\left.X^{2}=32.33, d f=18, P=0.02 ; I^{2}=44 \%\right)$, a low heterogeneity for the moderate category $\left(\chi^{2}=28.04, d f=20\right.$, $P=0.11 ; \quad I^{2}=29 \%$ ), and a moderate heterogeneity for the hard category $\left(\tau^{2}=1.19 ; \chi^{2}=68.42, d f=19\right.$, $\left.P<0.00001 ; I^{2}=72 \%\right)$. When comparing the sRPE between coaches and athletes in the three effort categories, a low heterogeneity was observed for the easy category $\left(\chi^{2}=1.18, d f=7, P=0.99 ; I^{2}=0 \%\right)$, a low heterogeneity for the moderate category $\left(\chi^{2}=0.69, d f=7\right.$, $\left.P=1.00 ; I^{2}=0 \%\right)$, and a low heterogeneity for the hard category $\left(\chi^{2}=0.65, d f=7, P=1.00 ; I^{2}=0 \%\right)$.

The overall RPE prescribed/intended/observed by the coaches showed no significant difference when compared to the RPE perceived by the athletes $(Z=1.64, P=0.10$, $\mathrm{SMD}=0.19$ [95\% CI -0.04 to 0.41$]$; small effect size, see Fig. 2). Likewise, no significant difference was observed when comparing the overall sRPE prescribed/intended/ observed by the coaches and that perceived by the athletes $(Z=0.32, P=0.75, \mathrm{SMD}=0.05[95 \% \mathrm{CI}-0.24$ to 0.33]; small effect size, see Fig. 3). This result indicated that the athletes perceived the same intensity and internal load prescribed/intended/observed by the coaches.

When comparing the RPE prescribed/intended/ observed by the coaches and that perceived by the athletes in the easy effort category, a significant difference was observed $(Z=2.03, P=0.04, \mathrm{SMD}=-0.44 \quad[95 \%$ CI -0.87 to -0.01 ]; small effect size, Fig. 4, top panel). Thus, the athletes perceived an intensity greater than the coaches prescribed/intended/observed. In the moderate effort category, no significant difference was observed when comparing RPE between coaches and athletes $(Z=0.34, P=0.74, \mathrm{SMD}=0.05[95 \% \mathrm{CI}-0.22$ to 0.31$]$; small effect size, see Fig. 4, middle panel. In the hard category, no significant difference was observed between the coaches prescribed/intended/observed and the athletes perceived $(Z=1.34, P=0.18, \mathrm{SMD}=0.41[95 \% \mathrm{CI}$ -0.19 to 1.00$]$; small effect size, Fig. 4 , bottom panel). This result indicated that the athletes perceived the same intensity prescribed/intended/observed by the coaches.

In the comparison between the sRPE prescribed/ intended/observed by the coaches and that perceived by the athletes in the easy effort category, a significant difference was observed $(Z=2.05, P=0.04, \mathrm{SMD}=-0.54$, 95\% CI [ -1.05 to -0.02$]$; moderate effect size, see Fig. 5, top panel). Thus, the athletes perceived an internal load greater than the coaches prescribed/intended/observed. In the moderate effort category, no significant difference was observed when comparing sRPE between coaches and athletes $(Z=0.59, P=0.56, \mathrm{SMD}=-0.15[95 \% \mathrm{CI}$ -0.66 to 0.36 ]; small effect size, see Fig. 5 , middle panel). In the category of hard effort, no significant difference was observed when comparing the SRPE prescribed/ intended/observed by the coaches and that perceived by the athletes $(Z=0.79, P=0.43, \mathrm{SMD}=0.20[95 \% \mathrm{CI}$ -0.30 to 0.71 ]; small effect size, see Fig. 5 , bottom panel). The results of the moderate and hard effort categories 


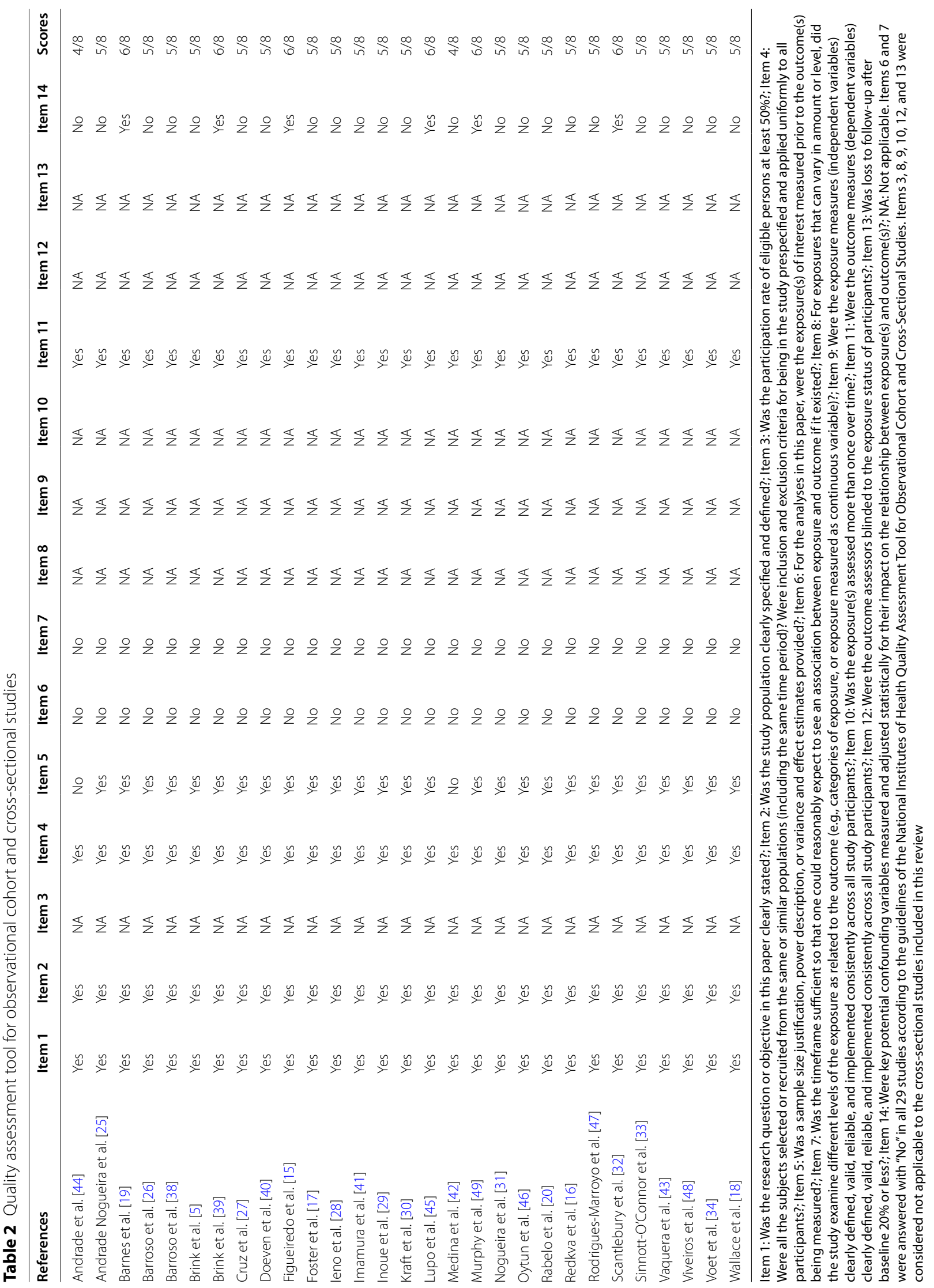




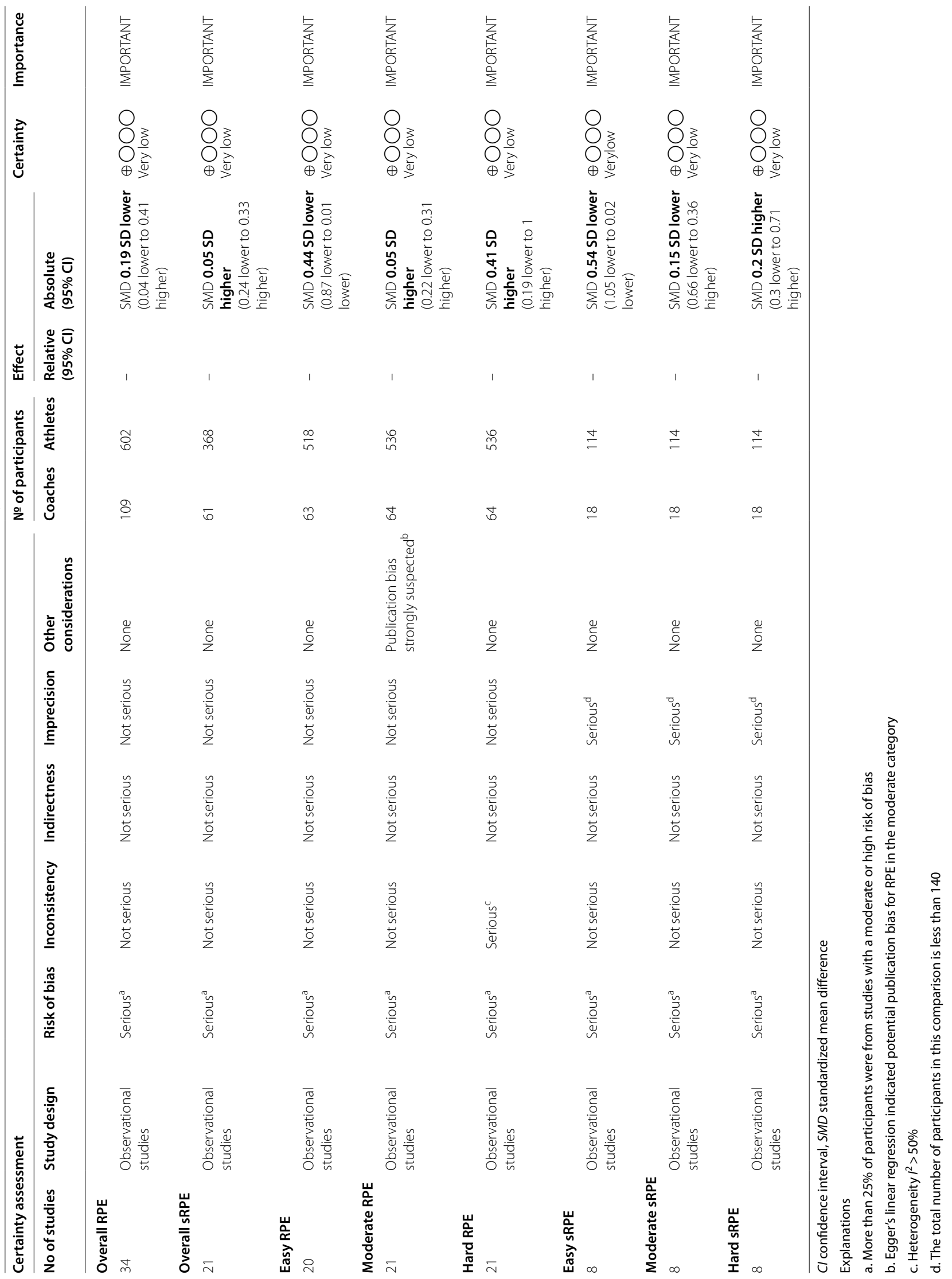




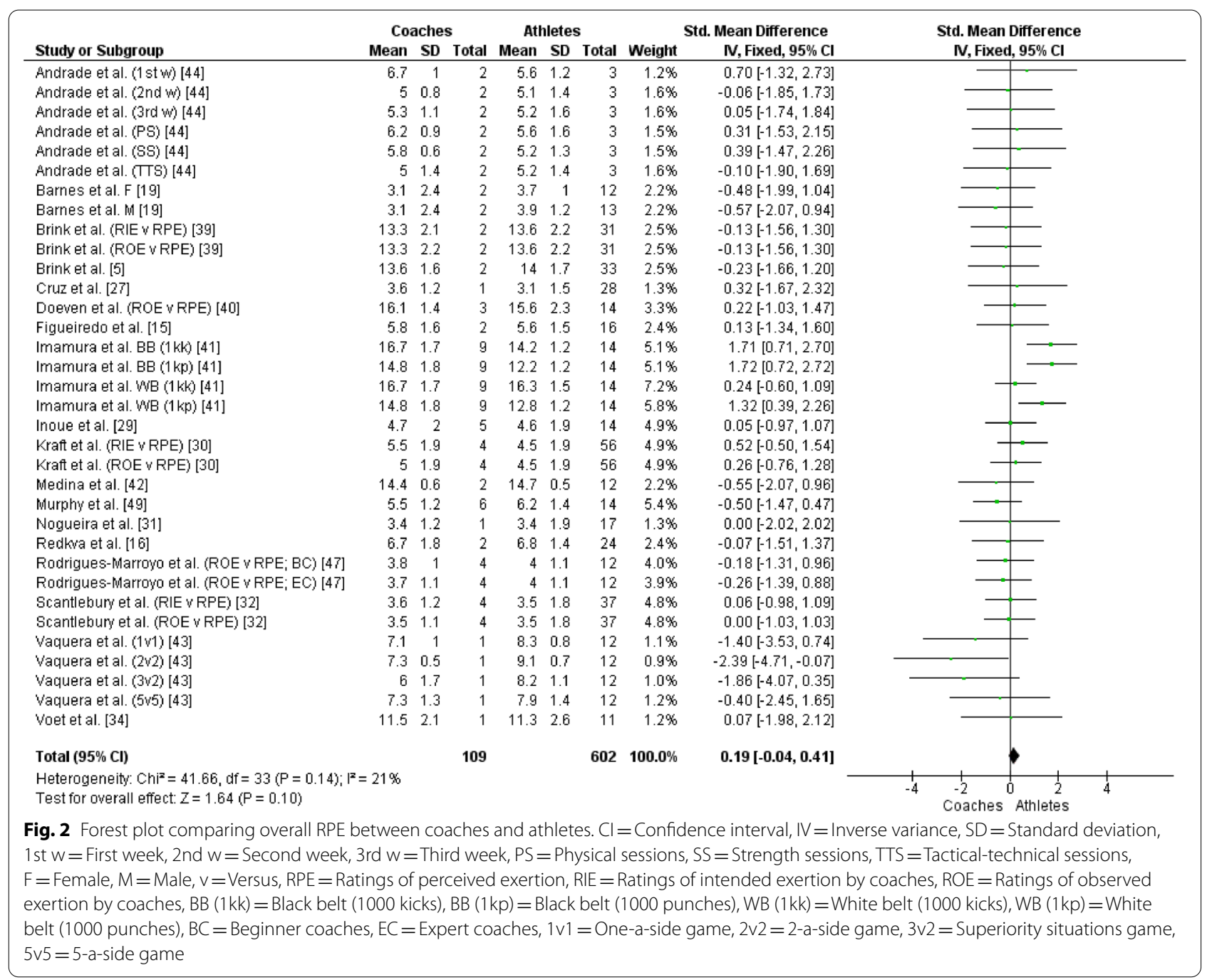

indicate that athletes perceived the same internal load prescribed/intended/observed by the coaches.

Egger's linear regression indicated no potential publication biases for overall RPE $(P=0.51)$, and for RPE in the easy $(P=0.37)$, and hard $(P=0.51)$ categories. However, Egger's linear regression indicated potential publication bias for RPE in the moderate category $(P=0.03)$. No potential publication bias was observed for overall sRPE $(P=0.22)$, and for sRPE in the easy $(P=0.10)$, moderate $(P=0.34)$, and hard $(P=0.68)$ categories, respectively. The funnel plots (Additional file 1: Figure S1 to S3) depict the distribution of these data.

\section{Discussion}

This systematic review and meta-analysis aimed to investigate whether there are differences between the training load perceived by athletes and that prescribed/intended/ observed by coaches. The main findings were: (1) No significant differences were observed between the overall
RPE and SRPE perceived by the athletes and those prescribed/intended/observed by the coaches (Figs. 2 and 3); (2) Significant differences were observed between the RPE and sRPE perceived by the athletes and those prescribed/intended/observed by the coaches in training sessions classified as easy (Figs. 4 and 5), in which the athletes perceived intensity and internal load greater than that prescribed/intended/observed by the coach; (3) No significant differences were observed between the RPE and SRPE perceived by the athletes and those prescribed/ intended/observed by the coaches in training sessions classified as moderate and hard (Figs. 4 and 5).

\section{Agreement and Disagreement on Training Load Between Athletes and Coaches}

The high-performance sport imposes intense training loads on athletes, establishing a complex relationship between an adequate application of these training loads and the recovery process. In this sense, the quantification 


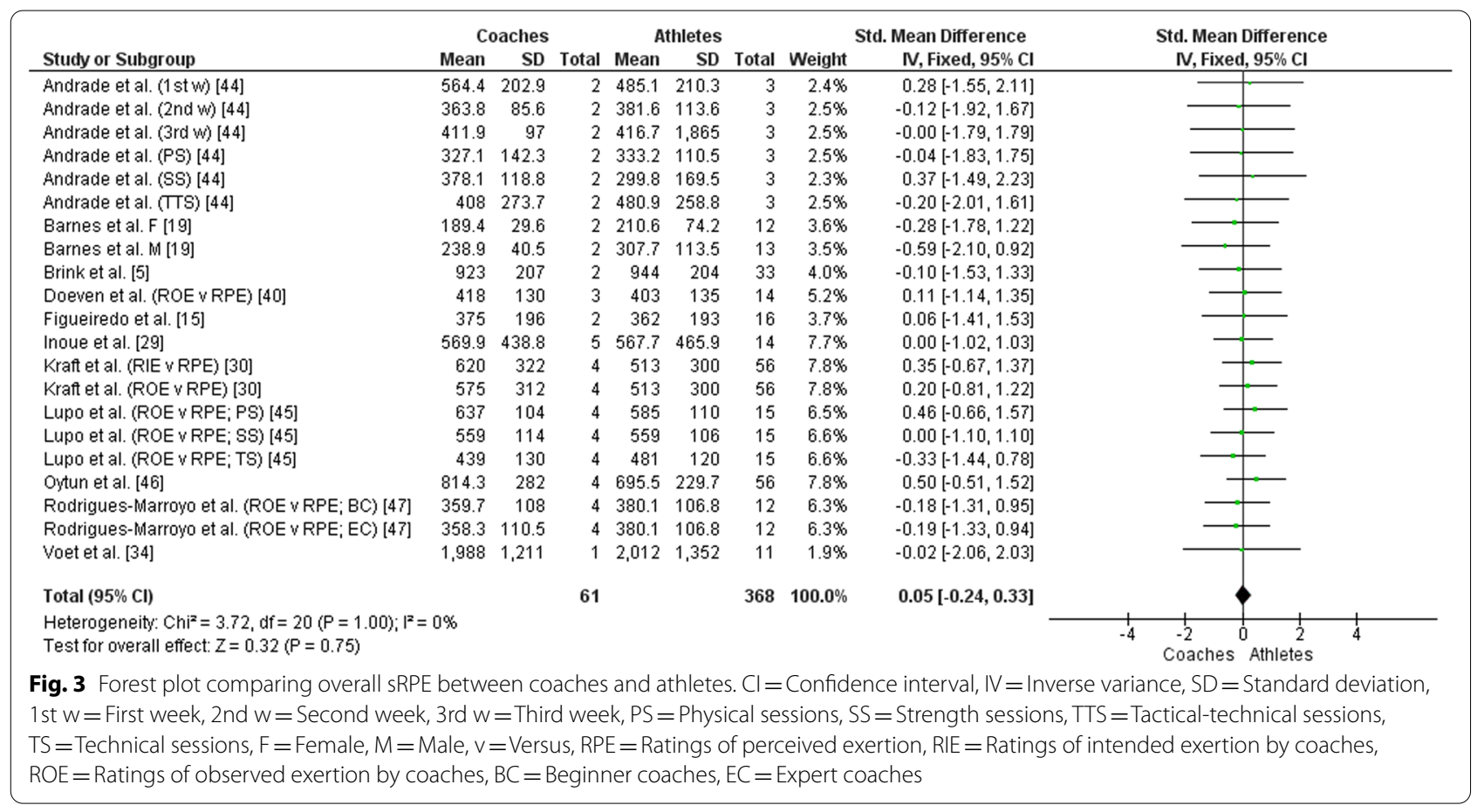

of training load becomes essential to monitor and prescribe a training program for athletes, thus ensuring increased performance [2]. Therefore, the coaches should know how each athlete perceives the prescribed load of successive training sessions [15]. To accurately prescribe training loads and interpret athlete responses, it is essential to establish an agreement between what was prescribed by the coach and what was perceived by the athlete. This review showed that overall RPE and SRPE were similar between athletes and coaches. This good relationship between coach and athlete is essential to achieve the established goals and optimize individual performance. However, significant differences were observed between the RPE and sRPE perceived by the athletes and those prescribed/intended/observed by the coaches in training sessions classified as easy.

The agreement and disagreement may be related to several factors such as differences in coach supervision during training sessions, physiological and psychosocial factors, communication between coaches and athletes, coach experience, athlete experience [19], competition atmosphere, crowd, motivation, competition outcome, sponsors [40], environmental factors such as temperature and humidity, and factors influencing athlete recovery (diet, sleep, personal stressors) [30].

\section{Scale Used}

The rationale for differences between the training load perceived by athletes and that prescribed/intended/ observed by coaches has not been fully elucidated. However, it seems not to be related to the scale used. There are a variety of scales that can be used to measure RPE. The Borg CR10 Scale, the Borg Scale 6-20, and a generic 0 -to-10-point scale without images using the Omni verbal cues for adults (OMNI) were also used in this review. In addition, we observed different cutoff values to classify sessions into easy, moderate, and hard. However, the results seem not to be influenced by scale choice or cutoff values. A good verbal anchorage seems to be important and will allow the athlete to define the intensity zones more precisely $[13,50]$. It is essential that athletes understand the scale and accurately link physical sensations to a number on the scale during different exercise intensities [51]. Different questions have been used to measure

(See figure on next page.)

Fig. 4 Forest plot comparing RPE between coaches and athletes in three effort categories, easy (top panel), moderate (middle panel) and hard (bottom panel). $\mathrm{Cl}=$ Confidence interval, IV = Inverse variance, $\mathrm{SD}=$ Standard deviation, $\mathrm{F}=$ Female, $\mathrm{M}=\mathrm{Male}, \mathrm{y}=$ Years old, $\mathrm{v}=$ Versus, $\mathrm{RPE}=$ Ratings of perceived exertion, RIE $=$ Ratings of intended exertion by coaches, $\mathrm{ROE}=$ Ratings of observed exertion by coaches, Pre- $\mathrm{S}=$ Pre-season, $\mathrm{C} 1=$ First competitive period, $\mathrm{IC}=$ intercompetition period, $\mathrm{C} 2=$ Second competitive period 


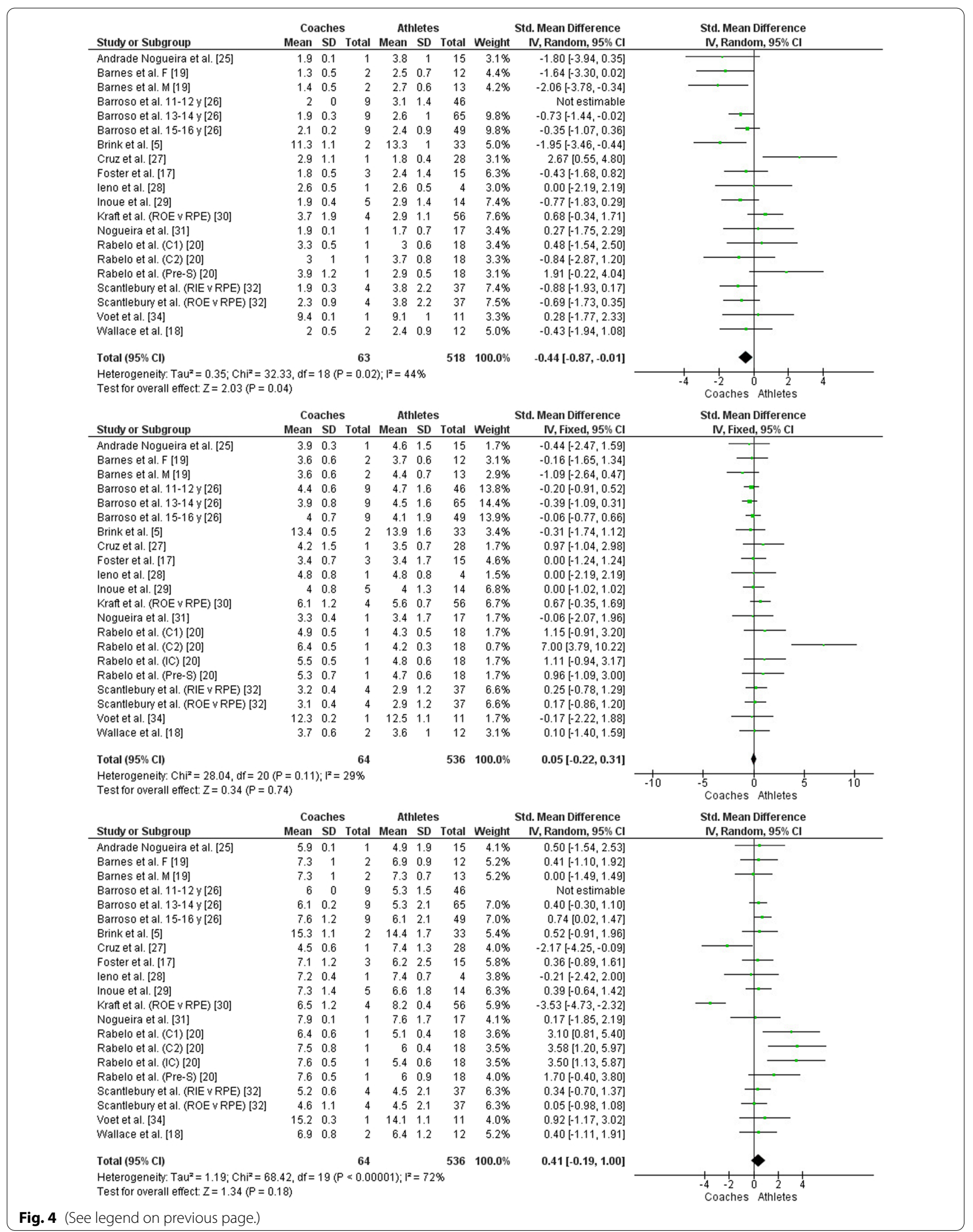




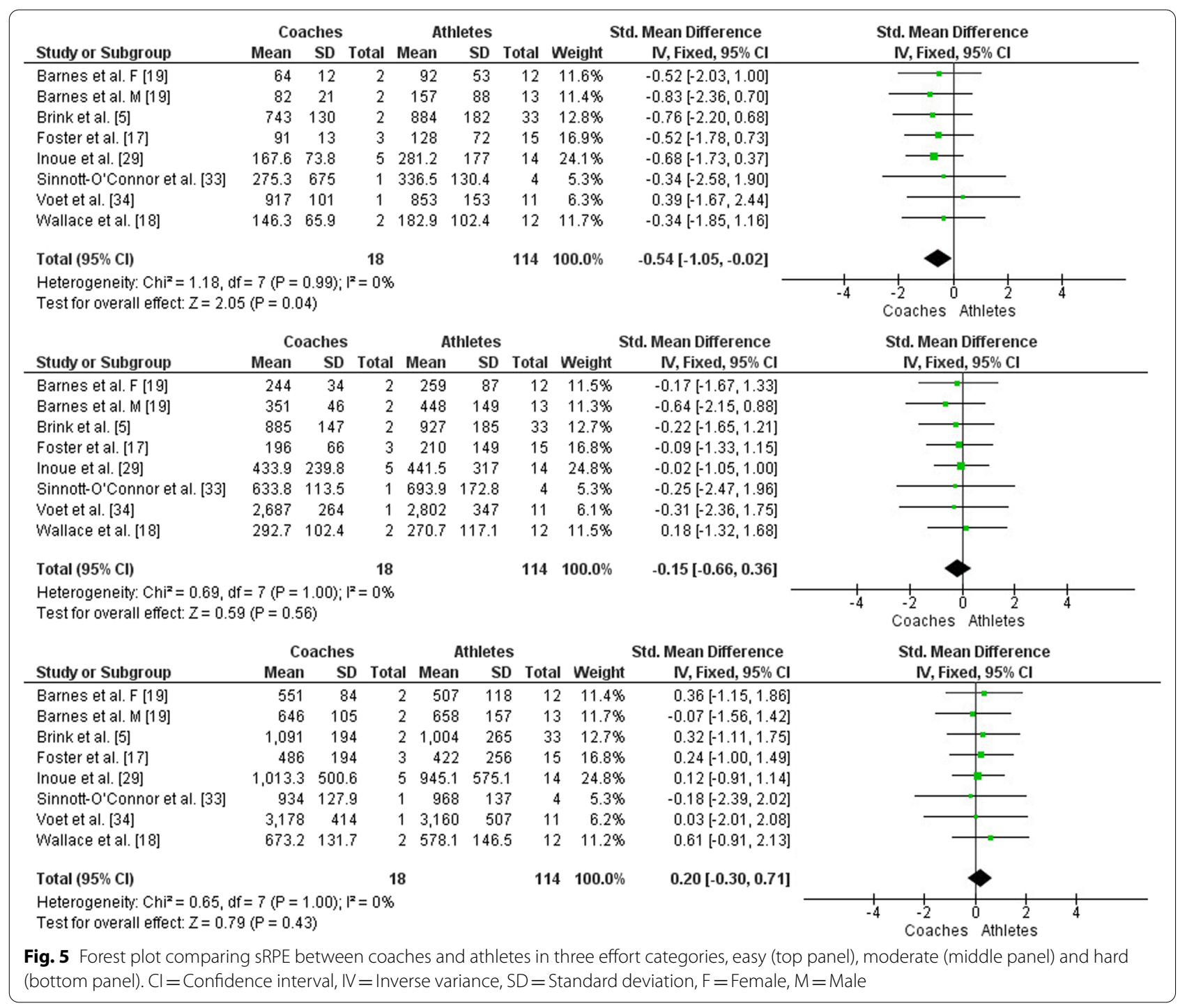

the RPE and sRPE as, for example, "How hard was your session?", "How was your training session today?", "How was your workout?". A slight difference in the text and the way the question is asked can influence the athlete's perception and response, making comparisons between studies difficult. However, there is no knowledge about the influence of these small changes on the accuracy of the tool's use by coaches [52]. In this sense, these different questions do not seem to influence the results [22, 53]. Thus, there is no ideal scale but the need for familiarization and good verbal anchoring [54]. Besides, Coyne et al. [54] reported that a 100-point RPE category ratio scale (CR100) should be considered to improve sensitivity. The CR100 may have greater sensitivity due to more verbal anchors and a finer grading than the CR10 scale [54]. However, counter-evidence shows interchangeability between the CR100 and CR10 scales $[55,56]$. In addition, no study included in this systematic review and meta-analysis used the CR100 scale.

\section{Age and Sporting Experience}

The agreement/disagreement between coach and athlete can also be influenced by age and sporting experience [15]. Agreement between coaches and athletes tended to increase with age and experience. Based on the results of Barroso et al. [26], it is conceivable that more experienced athletes may perceive effort better than less experienced athletes due to greater variability in stimuli during their years of training. This variability in intensity can improve RPE, allowing athletes to experience and identify various physiological changes, thus creating an internal anchor for their efforts. Another critical point is that the instructions given to younger athletes must be clearly defined, as there is a lack of 
sports maturity to accurately perceive the intensity of the training load [26]. Misunderstanding instructions can induce athletes to perform tasks at different intensities from those previously planned, affecting RPE. Thus, coaches must be concerned with how to provide information to their athletes. However, more studies are needed to understand better how instruction can affect the relationship between coaches and athletes' RPE. Furthermore, it seems important that young athletes perform training at different intensities to improve their intensity effort perception [26].

\section{Observed RPE/sRPE}

Brink et al. [39] reported that coaches adjust their perceptions after observing training sessions; however, the incompatibility with players' perceptions remained. In fact, previous findings suggest coaches cannot accurately observe the internal load of players $[47,49]$. Scantlebury et al. [32] found that the level of agreement between coach and athlete RPE improved following training with coaches altering their RPE to align with the athlete's. They found the relationship between coach observed and athlete perceived RPE to improve compared to coach intended and athlete perceived RPE. To reduce issues arising from the over/under-prescription of training load, coaches must ensure that desired athlete responses to training are being achieved [32]. Importantly, the coach could re-align the training load if there is a mismatch. The incompatibility can be observed through daily monitoring of recovery and applied training loads. In this sense, coaches should intervene, increasing/decreasing training intensity and/or volume. The underestimation of RPE and sRPE as seen during easy training sessions may predispose the athlete to overuse injury or nonfunctional overreaching through an inability to handle the excess load [32].

\section{Endurance Capacity}

An individual characteristic influencing RPE is the intermittent endurance capacity [57]. For example, coaches estimate that athletes with a higher intermittent endurance capacity will perceive training to be less intense [39]. It is noteworthy that this characteristic is more evident in team sports. Furthermore, Barroso et al. [38] reported that the greater volume and distance of repetition during interval training influence the classification of the subjective perception of the session, increase the inter-individual variability, and affect the relationship between coaches and athletes. In this sense, care must be taken when prescribing sessions with greater volume and distance.

\section{Effort Categories and Female/Male Athletes}

There is a tendency to prescribe moderate-intensity training loads [58]. Gearhart et al. [51] proposed that trained athletes can more easily identify the intensity levels they experience most frequently. The discrepancy between athletes and coaches in the easy category may be psychophysiological [6]. There is a trend for athletes to report perceptions of moderate-intensity, which would be the pleasure perception zone. In this sense, low intensity cannot motivate [59, 60]. In addition, since easy or moderate training sessions often follow hard sessions, another explanation could be that coaches may have a misconception of the athlete's physiological state after the training load from the previous session. Although coaches expect an easy training session the day after a hard session, it is possible that athletes do not recover physically or psychologically enough to perceive this training as easy [19]. In an attempt to highlight to coaches which athletes are entering sessions not recovered, quantitative markers could be used to assess recovery (e.g., perceived recovery status scale, total quality of recovery scale, well-being indices, etc.) [56, 61, 62].

There is a lack of data comparing the perceptions of female athletes to coaches in any sport or discipline. In this sense, Barnes' study [19] compared the perceptions of training doses between coaches and male and female cross-country runners. Twenty-five highly-trained crosscountry runners (13 male and 12 female) were recruited. The results showed that men and women rated coachintended easy sessions significantly harder during each month of the season. Men rated moderate intensity sessions significantly higher than coaches, whereas females rated hard intensity sessions significantly lower than coaches. There was no difference between males' and coaches' hard sessions or females' and coaches' moderate sessions. Therefore, men and women report different RPE/sRPE in moderate and hard sessions [19]. The reasons for these discrepancies between male and female athletes are unknown. Studies are controversial when comparing sexes on the perceived exertion scale. Some studies have reported differences in RPE between men and women using different exercise intensity markers (absolute vs. relative) [63, 64]. More recently, Rascon et al. [65] showed no differences in RPE in any of the three exercise intensities (low: $<2 \mathrm{mmol} / \mathrm{L}$, moderate: $2-4 \mathrm{mmol} / \mathrm{L}$, and high: $>4 \mathrm{mmol} / \mathrm{L}$ ) between men and women.

\section{Type of Sport}

The coach-athlete mismatch observed in the easy effort category between the studies may be related to the type of sport. It is speculated that for individual sports (cycling, running, swimming), the prescription and monitoring of 
the training load are easier to perform when compared to team sports. This meta-analysis showed that there is a disagreement between coaches and athletes in the easy effort category regardless of the sport.

\section{Coaching Experience}

The coach's experience can also affect the intended/ observed training load. In a study included in this systematic review and meta-analyses, the RPE and sRPE of expert ( $>10$ years) and beginner $(\leq 1$ year) coaches were compared with the RPE and sRPE of volleyball athletes. The results showed the correspondence between the RPE and sRPE of athletes and coaches, regardless of experience.

\section{Training or Match/Games}

Good performance in competitions is an important goal of every athlete; however, the proportion of time spent on competitions is small compared to the time spent on training sessions. Doeven et al. [40] showed that the athletes' RPE was lower than ratings of observed exertion by coaches $(15.6 \pm 2.3$ and $16.1 \pm 1.4)$. In this sense, the coach overestimates match exertion. In contrast, Vaquera et al. [43] showed differences between athletes' and coaches' RPE in small-sided games $(P<0.002)$. The coach's RPE was lower when compared to the athletes' RPE. It is noteworthy that during competition trips, coaches may not be aware of the activities performed by athletes in the hours between training sessions. Lack of recovery or additional physical activity can result in accumulated fatigue and greater perceived exertion, even if the external load is similar. Previous research has identified that different intensities and training exercises can influence the mismatch between perceptions of effort $[47,49]$. For example, volleyball coaches underestimated players' RPE, particularly during high-intensity fitness exercises. However, the volume of technical-tactical exercises prescribed with moderate intensity corresponded to the dose of exercise received [47]. This result is congruent with data from elite junior tennis athletes, where coaches underestimated the overall RPE of the athletes' training session but not the RPE of the different types of individual exercises [49].

\section{Cognitive Demands}

Cognitively demanding tasks, such as new tactical concepts in training, can also increase RPE values [39, 66]. This is especially important because cognitive tasks impair physical performance [67]. Besides that, poor education of athletes has been recognized as a limiting factor when using subjective load monitoring procedures. If education around subjective load monitoring is not adequate, athletes may answer dishonestly in an attempt to manipulate future training sessions or to be selected for important competitions [54]. When planning the training, accounting for these issues is a complex and challenging task for coaches.

\section{Consequences of Divergent Perceptions Between Athletes and Coaches}

The effective alternation between training load and recovery theoretically improves sports performance [68]. Signs of inadequate recovery and maladaptation are evident when athletes train more intensely than planned for long periods [4]. In contrast, if athletes do not exert enough effort on the days planned to be intense, training stimuli may not be sufficient to provoke adequate adaptations [17]. The tendency of athletes to report perceptions of moderate training loads can have important implications for training. The tendency of the training load to regress to the mean rather than remain polarized (e.g., easy days and hard days) is considered a common training error [17]. It has been suggested that this decrease in the daily variability of the training load increases monotony [19], a known risk factor for overtraining [22]. Additionally, imprecision in the prescription and training load monitoring are essential factors that increase the risk of injuries and illnesses [22, 69].

For example, Brink et al. [5] reported that soccer athletes perceived the training loads prescribed by the coach to be easy and moderate as harder. At the same time, the athletes perceived the sessions prescribed by the coaches to be hard as easier. The study by Kraft et al. [30] found the opposite, with coaches reporting higher RPE during sessions rated as easy or moderate and lower RPE during sessions rated as hard. This pattern would be preferable because it would indicate greater training variation (i.e., easy and moderate training sessions easier than perceived, while hard sessions were more intense than coaches reported), thus decreasing training monotony and risk of overtraining. It is noteworthy that, unlike published studies, athletes' perceptions were used to classify training sessions as easy, moderate, and hard. Additionally, instead of prescribing RPE before the training session, the coaches in the study by Kraft et al. [30] reported RPE approximately $15-20$ min after observing the training session.

Daily control with feedback to coaches is key to decreasing the risk of injury and improving physical performance [69]. In addition, an increased RPE for a typical training session can be used as a guide for coaches to monitor individual increases in fatigue or decreases in fitness levels. On the other hand, a reduction in RPE for these standard training sessions may indicate adaptation to training [18]. 


\section{Association Between Coaches and Athletes}

A recent systematic review and meta-analysis investigated the relationship between coaches' rating of intended exertion and/or rating of observed exertion and athletes' reported rating of perceived exertion (for review, see [52]). A random effect meta-analysis based on 11 studies demonstrated a positive association of athletes' vs. coaches' rating of intended exertion of $r=0.62$. The pooled correlation from 7 studies of athletes' vs. coaches' rating on observed exertion was $r=0.64$. In this sense, there was a strong association between coach rating of intended exertion and/or rating of observed exertion and athlete-reported RPE. In our systematic review and metaanalysis, sixteen studies performed a correlation analysis between coaches' and athletes' rating of exertion. Based on the scale of magnitudes proposed by Hopkins (www. sportsci.org): $<0.1$, trivial; $0.1-0.3$, small; $0.3-0.5$, moderate; $0.5-0.7$, large; $0.7-0.9$, very large; $>0.9$, nearly perfect, the results (see Table 1$)$ ranged from small $(r=0.24)$ to nearly perfect $(r=0.93)$ correlation between coaches' and athletes' rating of exertion, thus showing a large variation among studies.

\section{Strength and Limitations}

Some aspects of this review should be highlighted. First, only cross-sectional studies that investigated the differences between the training load perceived by athletes and that prescribed/intended/observed by coaches were included. Although only studies with this design were retrieved in the literature search, we considered this aspect a limitation of this review. This observational characteristic does not determine causality. Second, studies included in this systematic review and meta-analysis were classified as having a low or moderate risk of bias. Future studies should report the main confounding variables to improve internal validity. On the other hand, Egger's linear regression analysis did not indicate potential publication biases that might have significantly influenced the results of overall, easy and hard RPE. However, a potential publication bias was found for RPE in the moderate category. Despite this, no significant difference was observed when comparing RPE between coaches and athletes, with a small effect size. For overall sRPE or in the three effort categories (easy, moderate, and hard), no potential publication biases were found in the present systematic review and meta-analysis. The cutoff values varied from study to study regarding the categorization used (easy, moderate, hard). We consider that familiarizing the instrument and anchoring the descriptors seems to be more important than the cutoff value used; therefore, we believe that the three effort categories did not influence our results. In addition, the 3-category comparison was used in the various studies included in this review [5, 17-20, 25-34]. Third, the certainty of evidence was very low using the GRADE approach, creating a high degree of uncertainty in these results. However, it is noteworthy that observational studies such as those included in this review start with low certainty of evidence. Finally, a limitation of the psychometric scales directly influencing results is the use of artifacts in the scales such as colors, verbal anchors, or figures. Changes in the original scales could influence the athletes' responses and the observed results. Thus, coaches and sports scientists must use the scales initially validated in their original format.

Summarizing this literature is essential to guide coaches' and sport scientists' decision-making in training programming, thus maximizing adaptive responses [6]. Any discrepancies between the program planned by the coach and that executed by the athletes can lead to incorrect prescription/execution of training loads, which are potential causes of the high incidence of negative results in sports training [17].

\section{Conclusion}

Based on the results presented, there is an agreement between coaches and athletes about the overall RPE and SRPE, and RPE and sRPE into moderate and hard effort categories. However, we found divergences between the RPE and sRPE prescribed/intended/observed by coaches and that perceived by the athletes in the easy effort category. Thus, despite a small disagreement, the use of these tools seems to be adequate for training monitoring. However, the certainty of evidence for these results was very low. More studies should be carried out controlling for the risk of bias, imprecision, and confounding factors to increase the certainty of evidence. Researchers, coaches, and athletes must carefully monitor the internal training load, thereby optimizing sports performance, decreasing negative outcomes, and ultimately preventing athletes from developing overtraining.

\section{Abbreviations}

RPE: Rating of perceived exertion; SRPE: Session rating of perceived exertion; RIE: Rating of intended exertion; ROE: Rating of observed exertion; CR10: Category ratio 10 scale; CR100: 100-Point RPE category ratio scale; OMNI: Perceived exertion scale; GPS: Global positioning system; PRISMA: Preferred reporting items for systematic reviews and meta-analyses; GRADE: Grading of recommendations assessment, development and evaluation; SMD: Standardized mean difference; Cl: Confidence interval; 95\% Cl: 95\% Confidence interval; ES: Effect size; IV: Inverse variance; SD: Standard deviation; mmol/L: Millimoles per liter; NR: Not reported; M: Males; F: Females; Yrs: Years; UCl: Union cycliste internationale; 1st w: First week; 2nd w: Second week; 3rd w: Third week; PS: Physical sessions; SS: Strength sessions; TTS: Tactical-technical sessions; TS: Technical sessions; BB: Black belt; WB: White belt; 1 kk: 1000 Kicks; 1 kp: 1000 Punches; BC: Beginner coaches; EC: Expert coaches; 1v1: One-a-side game; 2v2: 2-a-side game; 3v2: Superiority situations game; 5v5: 5-a-side game; Pre-S: Pre-season; C1: First competitive period; IC: Intercompetition period; C2: Second competitive period. 


\section{Supplementary Information}

The online version contains supplementary material available at https://doi. org/10.1186/s40798-022-00420-3.

Additional file 1. Search strategy and Funnel plots.

\section{Acknowledgements \\ Not applicable}

\section{Authors' contributions}

$\mathrm{Al}$ and $\mathrm{ES}$ designed the research. Al and PB conducted the searches and screening. Al and PB extracted the data, which were verified by ES. Al and ES performed the statistical analyses. Al drafted the manuscript, and all authors (PB, EC, EL and ES) edited and revised the final version of the manuscript. All authors read and approved the final manuscript.

\section{Funding}

No sources of funding or financial support were used to assist in the preparation of this manuscript.

\section{Availability of Data and Materials}

Data supporting the findings of this study are available from the corresponding author on request.

\section{Declarations}

Ethics Approval and Consent to Participate

Not applicable.

\section{Consent for Publication}

Not applicable.

\section{Competing interests}

Allan Inoue, Priscila dos Santos Bunn, Everton Crivoi do Carmo, Eduardo Lattari and Elirez Bezerra da Silva declare that they have no competing interests.

\begin{abstract}
Author details
${ }^{1}$ Exercise and Sport Sciences Postgraduate Program, Rio de Janeiro State University, Rio de Janeiro, Brazil. ${ }^{2}$ Research Group on Exercise and Health Science, Rio de Janeiro State University, Rio de Janeiro, Brazil. ${ }^{3}$ Exercise Sciences Research Laboratory, Physical Education Center Admiral Adalberto Nunes (CEFAN), Brazilian Navy, Rio de Janeiro, Brazil. ${ }^{4}$ Department of Physical Education, Senac University Center, São Paulo, Brazil. ${ }^{5}$ Physical Activity Sciences Postgraduate Program, Salgado de Oliveira University, Niterói, Brazil.
\end{abstract}

Received: 17 August 2021 Accepted: 13 February 2022

Published online: 04 March 2022

\section{References}

1. Halson SL. Monitoring training load to understand fatigue in athletes. Sports Med. 2014;44(Suppl 2):S139-47. https://doi.org/10.1007/s40279014-0253-z (Epub 2014/09/10)

2. Mujika I. Quantification of training and competition loads in endurance sports: methods and applications. Int J Sports Physiol Perform. 2017;12(Suppl 2):S29-217. https://doi.org/10.1123/ijspp.2016-0403 (Epub 2016/12/06)

3. McLaren SJ, Macpherson TW, Coutts AJ, Hurst C, Spears IR, Weston M. The relationships between internal and external measures of training load and intensity in team sports: a meta-analysis. Sports Med. 2018;48(3):64158. https://doi.org/10.1007/s40279-017-0830-z (Epub 2017/12/31).

4. Meeusen R, Duclos M, Foster C, Fry A, Gleeson M, Nieman D, et al. Prevention, diagnosis, and treatment of the overtraining syndrome: joint consensus statement of the European College of Sport Science and the American College of Sports Medicine. Med Sci Sports Exerc. 2013;45(1):186-205. https://doi.org/10.1249/MSS.0b013e318279a10a (Epub 2012/12/19).
5. Brink MS, Frencken WG, Jordet G, Lemmink KA. Coaches' and players' perceptions of training dose: not a perfect match. Int J Sports Physiol Perform. 2014;9(3):497-502. https://doi.org/10.1123/ijspp.2013-0009 (Epub 2013/11/16).

6. Impellizzeri FM, Marcora SM, Coutts AJ. Internal and external training load: 15 years on. Int J Sports Physiol Perform. 2019;14(2):270-3. https://doi.org/10.1123/ijspp.2018-0935 (Epub 2019/01/08)

7. Bourdon PC, Cardinale M, Murray A, Gastin P, Kellmann M, Varley MC, et al. Monitoring athlete training loads: consensus statement. Int J Sports Physiol Perform. 2017;12(Suppl 2):S2161-70. https://doi.org/10. 1123/IJSPP.2017-0208 (Epub 2017/05/04)

8. Thompson WR. Worldwide survey of fitness trends for 2017. J ACSM's Health Fitness J. 2016;20(6):8-17.

9. Foster C, Rodriguez-Marroyo JA, de Koning JJ. Monitoring training loads: the past, the present, and the future. Int J Sports Physiol Perform. 2017;12(Suppl 2):S22-8. https://doi.org/10.1123/ijspp.2016-0388 (Epub 2017/03/03)

10. Borresen J, Lambert MI. The quantification of training load, the training response and the effect on performance. Sports Med. 2009;39(9):77995. https://doi.org/10.2165/11317780-000000000-00000 (Epub 2009/08/21)

11. Manzi V, D'Ottavio S, Impellizzeri FM, Chaouachi A, Chamari K, Castagna C. Profile of weekly training load in elite male professional basketball players. J Strength Cond Res. 2010;24(5):1399-406. https://doi.org/10. 1519/JSC.0b013e3181d7552a (Epub 2010/04/14).

12. Coutts AJ. In the age of technology, Occam's razor still applies. Int J Sports Physiol Perform. 2014;9(5):741. doi: https://doi.org/10.1123/ IJSPP.2014-0353. Epub 2014/08/30

13. Foster C, Boullosa D, McGuigan M, Fusco A, Cortis C, Arney BE, et al. 25 Years of session rating of perceived exertion: historical perspective and development. Int J Sports Physiol Perform. 2021;16(5):612-21. https:// doi.org/10.1123/ijspp.2020-0599 (Epub 2021/01/29).

14. Haddad M, Stylianides G, Djaoui L, Dellal A, Chamari K. Session-RPE method for training load monitoring: validity, ecological usefulness, and influencing factors. Front Neurosci. 2017;11:612. https://doi.org/10. 3389/fnins.2017.00612 (Epub 2017/11/23).

15. Figueiredo DH, Figueiredo DH, de Assis Manoel F, Gonçalves HR, Dourado AC. Coaches' and young soccer players' training load perceptions during different training phases. Rev Andaluza de Med del Deporte. 2019;12(4):336-41.

16. Redkva PE, Gregorio da Silva S, Paes MR, Dos-Santos JW. The relationship between coach and player training load perceptions in professional soccer. Percept Mot Skills. 2017;124(1):264-76. doi: https://doi. org/10.1177/0031512516678727. Epub 2016/11/20.

17. Foster C, Heimann, Kara M., Esten, Phillip L., Brice, Glen, Porcari JP. Differences in perceptions of training by coaches and athletes. S Afr J Sports Med. 2001;8(2):3-7.

18. Wallace LK, Slattery KM, Coutts AJ. The ecological validity and application of the session-RPE method for quantifying training loads in swimming. J Strength Cond Res. 2009;23(1):33-8. doi: https://doi.org/ 10.1519/JSC.0b013e3181874512. Epub 2008/11/13.

19. Barnes KR. Comparisons of perceived training doses in champion collegiate-level male and female cross-country runners and coaches over the course of a competitive season. Sports Med Open. 2017;3(1):38. doi: https://doi.org/10.1186/s40798-017-0105-0. Epub 2017/10/19.

20. Rabelo FN, Pasquarelli BN, Goncalves B, Matzenbacher F, Campos FA, Sampaio J, et al. Monitoring the intended and perceived training load of a professional futsal team over 45 weeks: a case study. J Strength Cond Res. 2016;30(1):134-40. https://doi.org/10.1519/JSC.0000000000 001090 (Epub 2015/07/23)

21. Sanders D, Abt G, Hesselink MKC, Myers T, Akubat I. Methods of monitoring training load and their relationships to changes in fitness and performance in competitive road cyclists. Int J Sports Physiol Perform. 2017;12(5):668-75. https://doi.org/10.1123/ijspp.2016-0454 (Epub 2017/01/18)

22. Foster C. Monitoring training in athletes with reference to overtraining syndrome. Med Sci Sports Exerc. 1998;30(7):1164-8. https://doi.org/10. 1097/00005768-199807000-00023 (Epub 1998/07/15)

23. Drew MK, Finch CF. The relationship between training load and injury, illness and soreness: a systematic and literature review. Sports Med. 
2016;46(6):861-83. https://doi.org/10.1007/s40279-015-0459-8 (Epub 2016/01/30)

24. Moher D, Liberati A, Tetzlaff J, Altman DG, Group P. Preferred reporting items for systematic reviews and meta-analyses: the PRISMA statement. PLoS Med. 2009;6(7):e1000097. doi: https://doi.org/10.1371/journal. pmed.1000097. Epub 2009/07/22.

25. Andrade Nogueira FCd, Nogueira RA, Coimbra DR, Miloski B, Freitas VHd, Bara M. Internal training load: perception of volleyball coaches and athletes. Rev Bras Cineantropom Desempenho Hum. 2014;16(6):638-47.

26. Barroso R, Cardoso RK, do Carmo EC, Tricoli V. Perceived exertion in coaches and young swimmers with different training experience. Int $J$ Sports Physiol Perform. 2014;9(2):212-6. doi: https://doi.org/10.1123/ ijspp.2012-0356. Epub 2013/05/01.

27. Cruz R, Fretas JVd, Santos J, Castro PH, Siqueira R, Alves DL, et al. Comparison between the RPE planned by coach with perceived by youth athletes of track and field. Revista Brasileira de Ciência e Movimento. 2017;25(1):13-8.

28. Ieno C, Baldassarre R, Pennacchi M, La Torre A, Bonifazi M, Piacentini MF. Monitoring Rating of Perceived Exertion Time in Zone: A novel method to quantify training load in elite open-water swimmers? Int I Sports Physiol Perform. 2021:1-5. doi: https://doi.org/10.1123/ijspp.2020-0707. Epub 2021/03/25

29. Inoue A, do Carmo EC, de Souza Terra B, Moraes BR, Lattari E, Borin JP. Comparison of coach-athlete perceptions on internal and external training loads in trained cyclists. Eur J Sport Sci. 2021:1-7. doi: https://doi.org/ 10.1080/17461391.2021.1927198. Epub 2021/05/13.

30. Kraft JA, Laurent MC, Green JM, Helm J, Roberts C, Holt S. Examination of coach and player perceptions of recovery and exertion. J Strength Cond Res. 2020;34(5):1383-91. https://doi.org/10.1519/JSC.0000000000002538 (Epub 2018/03/01).

31. Nogueira FDA, Nogueira R, Miloski B, Cordeiro A, Werneck F, Bara FM. Comparison of the training load intensity planned by the coach with the training perceptions of the swimming athletes. Gazz Med Ital. 2015;174:1-2

32. Scantlebury S, Till K, SawczukT, Weakley J, Jones B. Understanding the relationship between coach and athlete perceptions of training intensity in youth sport. J Strength Cond Res. 2018;32(11):3239-45. https://doi.org/ 10.1519/JSC.00000000000002204 (Epub 2017/10/19)

33. Sinnott-O'Connor C, Comyns TM, Warrington GD. Validity of session-rate of perceived exertion to quantify training loads in paralympic swimmers. J Strength Cond Res. 2021;35(9):2611-5. doi: https://doi.org/10.1519/JSC. 0000000000003181. Epub 2019/05/03.

34. Voet JG, Lamberts RP, de Koning JJ, de Jong J, Foster C, van Erp T. Differences in execution and perception of training sessions as experienced by (semi-) professional cyclists and their coach. Eur J Sport Sci. 2021:1-9. doi: https://doi.org/10.1080/17461391.2021.1979102. Epub 2021/09/11.

35. Balshem H, Helfand M, Schunemann HJ, Oxman AD, Kunz R, Brozek J, et al. GRADE guidelines: 3 . Rating the quality of evidence. J Clin Epidemiol. 2011;64(4):401-6. doi: https://doi.org/10.1016/j.jclinepi.2010.07.015. Epub 2011/01/07.

36. Cohen J. Statistical power analysis for the behavioral sciences. Hillsdale: Lawrence Erlbaum Associates; 1988.

37. Higgins JP, Thompson SG, Deeks JJ, Altman DG. Measuring inconsistency in meta-analyses. BMJ. 2003;327(7414):557-60. https://doi.org/10.1136/ bmj.327.7414.557 (Epub 2003/09/06).

38. Barroso R, Salgueiro DF, do Carmo EC, Nakamura FY. The effects of training volume and repetition distance on session rating of perceived exertion and internal load in swimmers. Int I Sports Physiol Perform. 2015;10(7):848-52. doi: https://doi.org/10.1123/ijspp.2014-0410. Epub 2015/02/12.

39. Brink MS, Kersten AW, Frencken WGP. Understanding the Mismatch between coaches' and players' perceptions of exertion. Int I Sports Physiol Perform. 2017;12(4):562-8. doi: https://doi.org/10.1123/ijspp. 2016-0215. Epub 2016/09/13.

40. Doeven SH, Brink MS, Frencken WGP, Lemmink K. Impaired player-coach perceptions of exertion and recovery during match congestion. Int J Sports Physiol Perform. 2017;12(9):1151-6. https://doi.org/10.1123/ijspp. 2016-0363 (Epub 2017/01/18).

41. Imamura H, Yoshimura Y, Uchida K, Tanaka A, Nishimura S, Nakazawa AT. Heart rate, blood lactate responses and ratings of perceived exertion to 1000 punches and 1000 kicks in collegiate karate practitioners. Appl
Human Sci. 1997;16(1):9-13. https://doi.org/10.2114/jpa.16.9 (Epub 1997/01/01).

42. Medina JÁ, Lorente VM. Comparación entre las cargas planificadas y ejecutadas en el entrenamiento de fútbol sala: la doble escala. Retos Nuevas tendencias en educación física, deporte y recreación. 2016;29:48-52.

43. Vaquera A, Suarez-Iglesias D, Guiu X, Barroso R, Thomas G, Renfree A. Physiological responses to and athlete and coach perceptions of exertion during small-sided basketball games. J Strength Cond Res. 2018;32(10):2949-53. https://doi.org/10.1519/JSC.0000000000002012 (Epub 2017/08/02).

44. Andrade AD, de Moura Simim MA, Kassiano W, Andrés JMP, Almeidan $C D$ J, Maia N, et al. Do differences between the training load perceived by elite beach volleyball players and that planned by coaches affect neuromuscular function? Retos: nuevas tendencias en educación física, deporte y recreación. 2020;(38):632-6.

45. Lupo C, Ungureanu AN, Frati R, Panichi M, Grillo S, Brustio PR. Player session rating of perceived exertion: a more valid tool than coaches' ratings to monitor internal training load in elite youth female basketball. Int J Sports Physiol Perform. 2019:1-6. doi: https://doi.org/10.1123/ijspp.20190248. Epub 2019/11/07.

46. Oytun M, Açııada C, Hazır T, Tınazcı C. Athletes evaluation of training loads with different fitness levels in women's handball. Int J Appl Exer Physiol. 2020;9(11):99-107.

47. Rodriguez-Marroyo JA, Medina J, Garcia-Lopez J, Garcia-Tormo JV, Foster C. Correspondence between training load executed by volleyball players and the one observed by coaches. J Strength Cond Res. 2014;28(6):158894. https://doi.org/10.1519/JSC.0000000000000324 (Epub 2013/11/28).

48. Viveiros L, Costa EC, Moreira A, Nakamura FY, Aoki MS. Monitoramento do treinamento no judô: comparação entre a intensidade da carga planejada pelo técnico e a intensidade percebida pelo atleta. Rev Brasileira de Med do Esporte. 2011;17:266-9.

49. Murphy AP, Duffield R, Kellett A, Reid M. Comparison of athlete-coach perceptions of internal and external load markers for elite junior tennis training. Int J Sports Physiol Perform. 2014;9(5):751-6. doi: https://doi.org/ 10.1123/ijspp2013-0364. Epub 2013/11/16.

50. Robertson RJ. Perceived exertion for practitioners: rating effort with the OMNI picture system. Champaign: Human Kinetics; 2004.

51. Gearhart RF, Jr., Becque MD, Hutchins MD, Palm CM. Comparison of memory and combined exercise and memory-anchoring procedures on ratings of perceived exertion during short duration, near-peak-intensity cycle ergometer exercise. Percept Mot Skills. 2004;99(3 Pt 1):775-84. doi: https://doi.org/10.2466/pms.99.3.775-784. Epub 2005/01/15.

52. Paul $D$, Read $P$, Farooq $A$, Jones $L$. Factors influencing the association between coach and athlete rating of exertion: a systematic review and meta-analysis. Sports Med Open. 2021;7(1):1. doi: https://doi.org/10.1186/ s40798-020-00287-2. Epub 2021/01/07.

53. McGuigan M. Monitoring training and performance in athletes. Champaign: Human Kinetics; 2017.

54. Coyne JOC, Gregory Haff G, Coutts AJ, Newton RU, Nimphius S. The current state of subjective training load monitoring-a practical perspective and call to action. Sports Med Open. 2018;4(1):58. doi: https://doi.org/10. 1186/s40798-018-0172-x. Epub 2018/12/21.

55. Fanchini M, Ferraresi I, Modena R, Schena F, Coutts AJ, Impellizzeri FM. Use of CR100 scale for session rating of perceived exertion in soccer and its interchangeability with the CR10. Int J Sports Physiol Perform. 2016;1 (3):388-92. doi: https://doi.org/10.1123/ijspp.2015-0273. Epub 2015/08/27.

56. Clemente FM, Rabbani A, Araujo JP. Ratings of perceived recovery and exertion in elite youth soccer players: Interchangeability of 10-point and 100-point scales. Physiol Behav. 2019;210:112641. https://doi.org/10. 1016/j.physbeh.2019.112641 (Epub 2019/08/05).

57. Miloski B, Moreira A, Andrade FC, Freitas VH, Pecanha T, Nogueira RA, et al. Do physical fitness measures influence internal training load responses in high-level futsal players? J Sports Med Phys Fitness. 2014;54(5):588-94 (Epub 2014/10/02).

58. Foster C, Florhaug JA, Franklin J, Gottschall L, Hrovatin LA, Parker S, et al. A new approach to monitoring exercise training. I Strength Cond Res. 2001;15(1):109-15 (Epub 2001/11/16). 
59. Mageau GA, Vallerand RJ. The coach-athlete relationship: a motivational model. J Sports Sci. 2003;21(11):883-904. https://doi.org/10.1080/02640 41031000140374 (Epub 2003/11/25).

60. Jowett S. What makes coaches tick? The impact of coaches' intrinsic and extrinsic motives on their own satisfaction and that of their athletes. Scand J Med Sci Sports. 2008;18(5):664-73. https://doi.org/10.1111/j. 1600-0838.2007.00705.x (Epub 2008/01/23)

61. Selmi O, Goncalves B, Ouergui I, Levitt DE, Sampaio J, Bouassida A. Influence of well-being indices and recovery state on the technical and physiological aspects of play during small-sided games. J Strength Cond Res. 2021;35(10):2802-9. doi: https://doi.org/10.1519/JSC.0000000000003228. Epub 2019/08/14.

62. Kentta G, Hassmen P. Overtraining and recovery: a conceptual model. Sports Med. 1998;26(1):1-16. https://doi.org/10.2165/00007256-19982 6010-00001 (Epub 1998/09/18)

63. Robertson RJ, Moyna NM, Sward KL, Millich NB, Goss FL, Thompson PD. Gender comparison of RPE at absolute and relative physiological criteria. Med Sci Sports Exerc. 2000;32(12):2120-9. https://doi.org/10.1097/00005 768-200012000-00024 (Epub 2000/12/29).

64. Garcin M, Fleury A, Mille-Hamard L, Billat V. Sex-related differences in ratings of perceived exertion and estimated time limit. Int J Sports Med. 2005;26(8):675-81. https://doi.org/10.1055/s-2004-830440 (Epub 2005/09/15)

65. Rascon J, Trujillo E, Morales-AcuNa F, Gurovich AN. Differences between males and females in determining exercise intensity. Int J Exerc Sci. 2020;13(4):1305-16 (Epub 2020/10/13)

66. Macpherson TW, McLaren SJ, Gregson W, Lolli L, Drust B, Weston M. Using differential ratings of perceived exertion to assess agreement between coach and player perceptions of soccer training intensity: an exploratory investigation. J Sports Sci. 2019;37(24):2783-8. https://doi.org/10.1080/ 02640414.2019.1653423 (Epub 2019/08/20).

67. Brown DMY, Graham JD, Innes KI, Harris S, Flemington A, Bray SR. Effects of prior cognitive exertion on physical performance: a systematic review and meta-analysis. Sports Med. 2020;50(3):497-529. https://doi.org/10. 1007/s40279-019-01204-8 (Epub 2019/12/25).

68. Kiely J. Periodization paradigms in the 21 st century: evidence-led or tradition-driven? Int J Sports Physiol Perform. 2012;7(3):242-50. https:// doi.org/10.1123/ijspp.7.3.242 (Epub 2012/02/24).

69. Brink MS, Visscher C, Arends S, Zwerver J, Post WJ, Lemmink KA. Monitoring stress and recovery: new insights for the prevention of injuries and illnesses in elite youth soccer players. Br J Sports Med. 2010;44(11):809-15. https://doi.org/10.1136/bjsm.2009.069476 (Epub 2010/06/01).

\section{Publisher's Note}

Springer Nature remains neutral with regard to jurisdictional claims in published maps and institutional affiliations.

\section{Submit your manuscript to a SpringerOpen ${ }^{\circ}$ journal and benefit from:}

- Convenient online submission

- Rigorous peer review

- Open access: articles freely available online

- High visibility within the field

- Retaining the copyright to your article

Submit your next manuscript at $\boldsymbol{\nabla}$ springeropen.com 